\title{
CLAVES DE LA COMPOSICIÓN CANTOLLANISTA EN LA ESPAÑA DE LA BAJA EDAD MEDIA: EL OFICIO RIMADO DE SAN FROILÁN, OBISPO DE LEÓN
}

\author{
KEY ASPECTS IN THE PLAINCHANT COMPOSITION IN LATE MEDIEVAL \\ SPAIN: THE RHYMED OFFICE OF ST. FROILANUS, BISHOP OF LEÓN
}

\author{
Santiago Ruiz Torres \\ Universidad de Salamanca \\ santruiz@usal.es
}

ORCID ID: 0000-0001-5286-8782

\begin{abstract}
Resumen
La composición de oficios en verso representa una de las formas de expresión litúrgica más íntimamente ligadas a la Baja Edad Media. El conocimiento del género dista, sin embargo, de ser completo, en parte por la escasa atención que ha recibido el canto llano tardío hasta fecha reciente, pero también por su marcado localismo. Muchos de estos oficios se concibieron, de hecho, como vehículo con el que honrar al santo titular de una iglesia o monasterio determinados. Ello, a la postre, ha condicionado que sus fuentes sean limitadas amén de dispersas, a menudo carentes de notación musical. Estas páginas tienen por objeto el estudio del oficio rimado de san Froilán (832-905), quien fuera ermitaño y luego obispo de León. El interés del mismo reside fundamentalmente en su conservación en dos versiones musicales distintas: la primera y más importante, un breviario de Sanctis de los siglos XIII-XIV conservado en el Archivo de la Catedral de Lugo, que transmite el oficio completo; y por otro lado, el procesional ms. 9 del Archivo Catedralicio de León, de fines del siglo XIV, con cinco responsorios. Fuera de la edición de sus textos y algunas noticias dispersas, nada se sabe de este repertorio. A partir de su análisis pormenorizado pretendemos conocer cuáles fueron las directrices técnicas y estéticas que guiaron su composición, así como su adecuación con el corpus gregoriano más primitivo. Las evidencias recabadas posibilitarán, asimismo, aproximarnos a la datación cronológica del oficio y posible ubicación de sus artífices.
\end{abstract}

1 Este estudio forma parte de las actividades desarrolladas desde el proyecto de investigación I+D Spanish Early Music Manuscripts (HAR2017-82931-P), dirigido por la profesora Carmen Julia Gutiérrez, de la Universidad Complutense de Madrid. De igual modo, ha contado con la financiación del proyecto de investigación de la Arts \& Humanities Research Council

\begin{abstract}
The composition of versified offices represents one of the forms of liturgical expression most closely linked to the late Middle Ages. Knowledge of the genre is, however, far from complete, partly because of the scarce attention that late plainchant has received until recently, but also because of its strong localism. In fact, many of these offices were composed as a vehicle to honor the patron saint of a particular church or monastery. In the long run, this has resulted in their sources being limited and scattered, often without musical notation. These pages aim to study the rhymed office of Saint Froilanus (832-905), who was a hermit and, later, bishop of Leon. Its interest lies primarily in its preservation in two different musical versions: the first and most important, which transmits the complete office, is in a breviary de Sanctis from the 13th and 14th centuries preserved in the Archive of the Cathedral of Lugo; the other musical version, with five responsories, is in the processional ms. 9 of the Archive of the Cathedral of Leon, copied at the end of the 14th century. Besides the edition of the texts and some scattered information, nothing is known about this repertoire. Through its detailed analysis we intend to learn what were the technical and aesthetic guidelines followed in its composition, as well as how it adapted to the most primitive Gregorian corpus. The evidence gathered will allow us to get closer to the chronological dating of the office and the possible geographical origin of its composers.
\end{abstract}

Doctrine, devotion, and cultural expression in the cults of medieval Iberian saints (Referencia AH/S006060/1), supervisado por la profesora Emma Hornby, de la Universidad de Bristol. Agradecemos a Juan Carlos Asensio, José Carlos Martín, Joaquín Montull y Juan Pablo Rubio su valiosa ayuda en el desarrollo de esta investigación. 
Palabras clave

Canto llano, poesía rítmica, oficio litúrgico, hagiografía, san Froilán, León, Lugo, Baja Edad Media.

\section{INTRODUCCIÓN}

Hoy nadie duda en considerar el canto gregoriano como un corpus musical genuinamente medieval. Su estudio a lo largo de tan dilatado tiempo dista, sin embargo, de ser equilibrado, siendo las composiciones carolingias y poscarolingias (ca. 850-1100) las que han acaparado mayor atención entre los especialistas. Semejante parcialidad encuentra su origen en la línea de trabajo impulsada por los monjes de Solesmes a finales del siglo XIX, centrada en la investigación de los códices más primitivos. Otro factor que explica esta desatención, poco reparado por la literatura científica, es el carácter marcadamente local del repertorio tardío. En efecto, una vez consolidado el rito romano, allá por el siglo X, la nómina de celebraciones de alcance universal registró escasas admisiones; entre las más conocidas, las festividades del Corpus Christi, Domingo de Guzmán o Tomás de Canterbury. A la larga ese localismo contribuyó a que la proyección del corpus posgregoriano fuera limitada, a menudo circunscrita a la veneración del santo titular de una iglesia o monasterio.

A partir de 1100 empezó a ser frecuente la composición de oficios enteramente rimados con los que solemnizar las fiestas de nueva implantación. Salvo escasas excepciones, tales composiciones resultan poco conocidas. Hasta la fecha quien más se ha prodigado en su estudio ha sido el musicólogo inglés Andrew Hughes, responsable del mayor catálogo del repertorio, ${ }^{2}$ así como de la única publicación que analiza el corpus de manera global. ${ }^{3}$ Hughes es asimismo autor de varios trabajos de síntesis, de valor a la hora de familiarizarnos con sus peculiaridades más remarcables. ${ }^{4}$

2 Andrew Hughes, Late Medieval Liturgical Offices. Texts, Subsidia Mediaevalia, 23; Sources and Chants, Subsidia Mediaevalia, 24 (Toronto: Pontifical Institute of Medieval Studies, 1994 y 1996).

${ }^{3}$ Andrew Hughes, The Versified Office: Sources, Poetry, and Chants, 2 vols. (Lions Bay: The Institute of Mediaeval Music, 2011).

4 Andrew Hughes, "Rhymed Offices", en The Dictionary of the Middle Ages, 13 vols., ed. Joseph R. Strayer (New York: Charles Scribner's Sons, 1982-1989), vol. 10 (1988), pp. 366377; y, del mismo autor, "Late Medieval Plainchant for the Divine Office", en The New Oxford History of Music. III.1. Music as Concept and Practice in the Late Middle Ages (Oxford: Oxford University Press, 2001), pp. 31-96. De utilidad también son las valoraciones de conjunto proporcionadas por Peter Wagner, In-

\section{Key words}

Plainchant, rhythmic poetry, liturgical office, hagiography, Froilanus, Leon, Lugo, late Middle Ages.

Como tónica habitual, las restantes aportaciones han tenido como punto de mira un único oficio. El panorama ibérico se revela si cabe más desalentador. ${ }^{5}$ En general, existe la impresión de que fue un género poco cultivado en comparación con otras regiones europeas, en particular las más septentrionales. ${ }^{6}$ Pese a ello, manejamos cifras compositivas bastante considerables: sólo en Analecta Hymnica se da noticia de 70 oficios rimados con difusión peninsular.

Estas páginas tienen por objeto el estudio de uno de

troduction to the Gregorian Melodies. A Handbook of Plainsong I (London: The Plainsong \& Mediæval Music Society: 1907, $2^{\text {a }}$ ed.), pp. 260-275; y David Hiley, Western Plainchant (Oxford: Clarendon Press, 1993), pp. 273-279.

${ }^{5}$ Dentro de los escasos trabajos, la vocación musicológica resulta perceptible sobre todo en Santiago Ruiz Torres, "El oficio de la Traslación del apóstol Santiago en la Baja Edad Media: a propósito de un fragmento de antifonario hallado en la catedral de Segovia”, Cuadernos de Estudios Gallegos, LVIII/124 (2011), pp. 79-98; y Manuel Pedro Ferreira, "The Lisbon Office for the Translation of St. Vicent", en A Musicological Gift: Libro Homenaje for Jane Morlet Hardie, ed. Kathleen Nelson y Maricarmen Gómez (Lions Bay: The Institute of Mediaeval Music, 2013), pp. 57-86. Por su parte, Susana Zapke, "El oficio de San Indalecio en el antifonario de Santa Cruz de la Serós, s. XI-XII”, Aragonia Sacra, 6 (1991), pp. 181-198, analiza el oficio de san Indalecio desde las perspectivas litúrgica y hagiográfica, sin apenas reparar en consideraciones textuales y musicales. La composición poética constituye el foco de atención del trabajo de Estrella Pérez, "Cantus in Laudem Virginis: el oficio poético de Juan Gil de Zamora”, Studia Zamorensia, 13 (2014), pp. 109-123, sobre el oficio rimado a la Virgen escrito por Juan Gil de Zamora. Sobre esta última composición, conviene aclarar que se trata de un oficio no musicalizado.

6 Véase Wagner, Introduction to the Gregorian Melodies, pp. 273-74. Hughes, "Late Medieval Plainchant", pp. 55-56, especialmente p. $56, n$. 75 , admite, con todo, que esta apreciación puede resultar engañosa porque muchas de las fuentes españolas conservadas se asocian a grandes libros de coro, pocas veces inventariados y en general de difícil acceso para el estudio. En Portugal se tiene constancia de dos oficios en verso con origen medieval, de los cuales sólo uno conserva parcialmente música; véase Ferreira, "The Lisbon Office", pp. 68-69, n. 28.

${ }^{7}$ Guido Maria Dreves, ed., Analecta Hymnica Medii Aevi XVII. Hymnodia Hiberica (Leipzig: O.R. Reisland, 1894). En total, 10 de los 55 volúmenes de que consta la colección se destinan íntegramente a este repertorio, a los que hay que sumar además otros pocos oficios diseminados en distintos ejemplares. 
estos oficios en verso; en concreto, el de san Froilán (ca. 832-905), monje eremita y patrón de las diócesis de Lugo (locus nascendi) y León, donde fue obispo entre los años 900 a 905 . Su principal atractivo reside en el hecho de conservarse en dos manuscritos con música provenientes de localizaciones distintas: el primero y más importante, un breviario de Sanctis de los siglos XIII-XIV conservado en el Archivo de la Catedral de Lugo [Lu], que transmite el oficio completo (fols. $352 \mathrm{v}-359) ;{ }^{8}$ y por otro lado, el procesional ms. 9 del Archivo Catedralicio de León [Le9], de fines del siglo XIV, con cinco responsorios, uno de ellos en forma de íncipit (fols. 28-30). ${ }^{9} \mathrm{El}$ foco de atención lo pondremos, no obstante, en la primera fuente, fundamentalmente porque recoge melodías de nueva creación. Los cantos en Le9, como mostraremos más

${ }^{8}$ El códice ha sido objeto de estudio en diversas publicaciones: Xosé Fernández Fernández, "O misal lucense, singular texto liturxico do Arquivo da Catedral”, Lucensia, 6 (1993), pp. 71-84; y Manuel Rey Olleros, "La notación aquitana en el códice de Lugo (S. XIII): testimonio de un repertorio musical de Galicia (España) y su aplicación pedagógica", tesis doctoral, Pontificio Istituto di Musica Sacra, 2012, trabajo luego resumido en "El breviario de Lugo: su música", Annuarium Sancti Iacobi, 1 (2012), pp. 237 286. El religioso gallego hace una breve alusión a la notación del manuscrito en Manuel Rey Olleros, "Reminiscencias del culto al apóstol Santiago, a partir del códice Calixtino, en los libros litúrgicos de los siglos XII al XIV en la antigua provincia eclesiástica de Santiago", tesis doctoral, Universidad de Santiago de Compostela, 2009, pp. 158-162. El breviario cuenta, además, con una edición facsímil en línea a cargo de Wolodymyr Joseph Smishkewych, "An Online Digital Facsimile of the Lugo Codex", tesis doctoral, Indiana University, 2013, <https://scholarworks.iu.edu/dspace/ handle/2022/17230?show=full $>$ [consulta: 24/10/20]. La edición facsímil estuvo alojada inicialmente en $<\mathrm{http}$ ://opus.music.indiana. edu/s/lugocodex/index.php $>$, aunque a fecha de redacción de este artículo había dejado de ser válida. Todas las investigaciones citadas tienen como punto de partida la descripción proporcionada por Inocencio Portabales en su monumental Abecedario de la Catedral de Lugo (E-LUc estantería 60, 1923, ff. 255-379). Los cantos del códice de Lugo han sido indexados en la base de datos Musica Hispanica. Spanish Early Music Manuscripts Database <http:// musicahispanica.eu/source/22257> [consulta: 24/10/20].

9 A diferencia del breviario de Lugo, el procesional carece hasta hoy de estudio. Los pocos datos conocidos provienen de inventarios y repertorios litúrgicos, por lo general parcos en detalles. La información más completa nos la proporcionan José Janini, Manuscritos litúrgicos de las Bibliotecas de España. I. Castilla y Navarra (Burgos: Aldecoa, 1977), pp. 120-121 (núm. 135); y Michel Huglo, Les manuscrits du processional. I. Autriche a Espagne (Munich: G. Henle Verlag, 1999), pp. 304-305. adelante, reutilizan composiciones previas del Común de santos. En el Archivo Histórico Provincial de León se localiza además un fragmento de antifonario del siglo XVI con varios cantos en honor al santo; en este caso, hemos rehusado su estudio por el escaso número de piezas transmitido y por desconocer la iglesia de procedencia. ${ }^{10}$ Los textos del oficio constan además en el ms. 240 de la Biblioteca Nacional de España, un breviario de la Orden militar de Santiago copiado en el siglo XV [Sant]. Hasta la fecha contamos con tres ediciones del oficio poético de san Froilán: la de Analecta Hymnica, de fines del siglo XIX, ${ }^{11}$ la que publicara Antolín López Peláez en 1911, ${ }^{12}$ y la más reciente a cargo de Andrew Hughes en formato electrónico. ${ }^{13}$ La música, en cambio, no ha sido todavía editada, laguna que esperamos subsanar próximamente.

A partir de este trabajo pretendemos arrojar luz sobre los criterios técnicos y estéticos que guiaron la composición del oficio rimado del santo lucense y su adecuación con el corpus gregoriano primitivo. Para ello, combinamos dos niveles de análisis complementarios: el primero aborda el texto, dirigido a descubrir sus cualidades poéticas y fuentes de inspiración literaria; y el segundo tiene como meta la propia música, la cual estudiaremos desde el doble eje de estructuras modales y melódicas. Por último, a partir de las evidencias reunidas trataremos de averiguar la datación del oficio y posible ubicación de sus artífices.

${ }^{10}$ E-Lp, Fondos Especiales Va. 64. Sobre este manuscrito, véase Taurino Burón Castro, "Fragmentos de códices litúrgicos conservados en el Archivo Histórico Provincial de León”, en León y su historia: miscelánea histórica de temas leoneses, 8 vols. (León: Centro de Estudios e Investigación "San Isidoro", 1969-2003), vol. 6 (2000), pp. 369-370. El fragmento recoge cuatro cantos del oficio de san Froilán, dos de ellos incompletos; según su orden de aparición, primero figura un extracto de la doxología de un responsorio sin identificar, a continuación el himno Fugiendo mundi pompam, luego la antífona de Magníficat $O$ quanto desiderio y, por último, el inicio de la antífona In amore jugiter, que sitúa en las segundas vísperas. Las antífonas constan en Lu si bien con melodías diferentes.

11 Dreves, Analecta Hymnica Medii Aevi XVII, pp. 95-98 (núm. 32).

12 Antolín López Peláez, Vida póstuma de un santo (El culto de San Froilán) (Madrid: Imp. Hijos de Gómez Fuentenebro, 1911), pp. 191-200.

${ }^{13}$ Hughes, Late Medieval Liturgical Offices. Texts, referencia FR51. La edición, alojada en disco magnético, puede ser consultada además en <http://hlub.dyndns.org/projekten/ webplek/CANTUS/cgi-bin/LMLO/LMLO.cgi?X=FR51> [consulta 24/10/20]. 


\section{LAS REDACCIONES MUSICALES}

La versión del oficio de san Froilán transmitida por Lu comprende un total de 28 cantos propios. En la siguiente Tabla 1 damos cuenta de su relación, así como de otra serie de informaciones de interés para el posterior análisis:

\begin{tabular}{|c|c|c|c|c|}
\hline Oficio & Género & Pieza & Modo & Forma poética \\
\hline $\mathrm{V} 1$ & $\mathrm{~A}$ & Ad honorem patris & 1 & Verso de 10 sílabas \\
\hline V1 & $\mathrm{R}$ & Incombusti divina gratia ${ }^{14}$ & - & Verso de 10 sílabas \\
\hline V1 & $\mathrm{A}$ & O quanto desiderio & 6 & Dímetro yámbico \\
\hline $\mathrm{M}$ & $\mathrm{I}$ & Adsunt Froilani & 1 & Verso de 10 sílabas \\
\hline $\mathrm{M}$ & $\mathrm{A}$ & Natus in suburbio & 1 & Goliárdica \\
\hline $\mathrm{M}$ & $\mathrm{A}$ & Concupivit heremum & 2 & Goliárdica \\
\hline $\mathrm{M}$ & $\mathrm{A}$ & Prunas cultor & 3 & Goliárdica \\
\hline $\mathrm{M}$ & $\mathrm{R}$ & Devergente jam solis radio & 1 & Verso de 10 sílabas \\
\hline $\mathrm{M}$ & $\mathrm{R}$ & Benedicti professus & 2 & Verso de 10 sílabas \\
\hline $\mathrm{M}$ & $\mathrm{R}$ & Constitutus in pueritia & 2 & Verso de 10 sílabas \\
\hline $\mathrm{M}$ & $\mathrm{A}$ & Froilanus prospicit & 4 & Goliárdica \\
\hline $\mathrm{M}$ & $\mathrm{A}$ & Varias vir optimus & 5 & Goliárdica \\
\hline $\mathrm{M}$ & $\mathrm{A}$ & Os columba rubea & 6 & Goliárdica \\
\hline $\mathrm{M}$ & $\mathrm{R}$ & Incombusti divina gratia & 6 & Verso de 10 sílabas \\
\hline $\mathrm{M}$ & $\mathrm{R}$ & Aedificavit triplex & 1 & Verso de 10 sílabas \\
\hline $\mathrm{M}$ & $\mathrm{R}$ & Sancti patris nos juvent & 2 & Verso de 10 sílabas \\
\hline $\mathrm{M}$ & $\mathrm{A}$ & Patiens et humilis & 7 & Goliárdica \\
\hline $\mathrm{M}$ & A & Spiritus edocuit & 8 & Goliárdica \\
\hline $\mathrm{M}$ & $\mathrm{A}$ & Pie pastor sanctae & 1 & Verso de 10 sílabas \\
\hline $\mathrm{M}$ & $\mathrm{R}$ & Exaltatur lucerna & 1 & Verso de 10 sílabas \\
\hline $\mathrm{M}$ & $\mathrm{R}$ & Urbs non latet & 6 & Verso de 10 sílabas \\
\hline $\mathrm{M}$ & $\mathrm{R}$ & Opem nobis benigne & 1 & Verso de 10 sílabas \\
\hline $\mathrm{L}$ & $\mathrm{A}$ & In amore jugiter & 1 & Goliárdica \\
\hline $\mathrm{L}$ & $\mathrm{A}$ & Contemplatur jugiter & 2 & Goliárdica \\
\hline $\mathrm{L}$ & $\mathrm{A}$ & De salute populi & 3 & Goliárdica \\
\hline $\mathrm{L}$ & A & Invitus assumitur & 4 & Goliárdica \\
\hline $\mathrm{L}$ & A & Subditos edocuit & 5 & Goliárdica \\
\hline $\mathrm{L}$ & $\mathrm{A}$ & O lumen spectabile & 6 & Goliárdica \\
\hline $\mathrm{V} 2$ & $\mathrm{~A}$ & Salve sancte praesul & 1 & Verso de 10 sílabas \\
\hline
\end{tabular}

Tabla 1. Lista de cantos propios del oficio rimado de san Froilán. Siglas y abreviaturas empleadas: A = antífona; $\mathrm{I}=$ antífona de invitatorio; $\mathrm{L}=$ laudes; $\mathrm{M}$ = maitines; $\mathrm{R}=$ responsorio; $\mathrm{V} 1$ = primeras vísperas; $\mathrm{V} 2$ = segundas vísperas.

${ }^{14}$ Se corresponde con el responsorio cuarto de maitines, aunque aquí figura sólo en forma de íncipit sin notación. Al tratarse de un canto repetido, no computa en el global de 28 cantos propios. 
De la lectura de la anterior tabla se desprende que la nueva composición de cantos afecta tan solo a antífonas y responsorios, un modus procedendi habitual en los oficios poéticos bajomedievales. Su distribución además se restringe a las horas de mayor relieve litúrgico: vísperas, maitines y laudes. Las completas muy rara vez incorporan formularios nuevos, mientras que los rezos de prima, tercia, sexta y nona tradicionalmente repiten las antífonas 2 a 5 de laudes. ${ }^{15}$

Lu incluye además otros cuatro cantos, todos vinculados a las celebraciones del Común de un confesor: por un lado, los himnos Iste confessor domini sacratus y Jesu redemptor omnium, inscriptos respectivamente en las primeras vísperas y maitines; y por otro, los versículos simples Non est inventus y Benedictionem omnium, el primero rubricado en ambos rezos de vísperas y el segundo en maitines. Todas las piezas aparecen en forma de íncipit y sólo el himno Jesu redemptor omnium añade notación musical. En relación con este grupo de cantos, quizás el elemento más sorpresivo sea la ausencia de himnos de nueva creación, fundamentalmente por las altas cifras compositivas que registra el género en la Península Ibérica a partir del siglo XIII. ${ }^{16}$ Esa extrañeza se ve si cabe acentuada al constatar la existencia de un himno propio a san Froilán; nos referimos a Fugiendo mundi pompam, transmitido por Sant ${ }^{17}$ y por el fragmento litúrgico del Archivo Histórico Provincial de León mencionado con anterioridad. ${ }^{18} \mathrm{Su}$ ausencia en Lu sugiere que pueda tratarse de una composición algo más tardía.

El oficio se completa con otros once ítems de naturaleza no musical: la capítula Ecce sacerdos, la colecta Exaudi domine preces y nueve lecciones históricas para el rezo de maitines, número que acredita su adscripción al esquema secular o romano. La capítula toma como base un texto muy conocido de la liturgia del Común de un confesor, extraído del Eclesiastés (Si 44:16 y 20) y adaptado también como antífona y responsorio. Mientras tanto, la colecta Exaudi domine preces surge como paráfrasis de otra oración recogida en el Sacramentario

15 Hughes, "Late Medieval Plainchant", p. 32.

16 Carmen Julia Gutiérrez, "Procedimientos de creación y adaptación en los himnos litúrgicos medievales en España: la composición de un repertorio", Revista de Musicología, 27/2 (2004), p. 829.

${ }^{17}$ E-Mn, ms. 240, ff. 427v (vísperas) y 430v (laudes). El breviario registra los cantos propios de san Froilán en la festividad de la traslación de sus reliquias (11 de agosto). Para la celebración de octubre se remite a dicha conmemoración.

18 Véase la nota 9.
Gregoriano. ${ }^{19}$ Por su parte, las lecciones tienen como referente la Vita Froilanis, ${ }^{20}$ transmitida por dos fuentes de la catedral de León: la Biblia visigótica ms. 6 (ff. 101r$101 \mathrm{v}$ ), copiada ca. 920, ${ }^{21}$ y el leccionario-homiliario ms. 52 (ff. 258r-260v), de finales del siglo XII o comienzos del XIII. ${ }^{22}$ La versión incluida en Lu apenas difiere de la de estos testimonios, salvo variantes ortográficas y sintácticas menores.

A diferencia de Lu, Le9 dispone tan solo cinco responsorios, uno de ellos en forma de íncipit: el que hace número cuatro con texto Sancte Froilane Christi. Se trata de una pieza desconocida en los testimonios completos del oficio [Lu y Sant], nacida como adaptación del responsorio Sancte N. Christi confessor, del Común de un confesor. ${ }^{23}$ Los restantes responsorios recogidos en Le9, según su orden de aparición, son Devergente jam solis, Benedicti professus, Constitutus in pueritia y Exaltatur lucerna, correspondientes, a su vez, con los números 1, 2, 3 y 7 de la serie responsorial de maitines. Las melodías,

19 Jean Deshusses, ed., Le Sacramentaire Grégorien: Ses principales formes d'après les plus anciens manuscrits, 3 vols. (Fribourg: Éditions Universitaires, 1971-1982), vol. 1 (1971), p. 271 (núm. 729).

${ }^{20}$ La Vita Froilanis cuenta con una edición crítica de José Carlos Martín, "La Vita Froilanis episcopi Legionensis (BHL 3180) (s. X): introducción, edición crítica y particularidades lingüísticas", en Parva pro magnis munera: Etudes de littérature latine tardo-antique et médiévale offertes à François Dolbeau par ses élèves, Instrumenta patristica et mediaevalia, 51 (Turnhout: Brepols, 2009), pp. 561-584. Dicho relato además ha sido traducido al castellano por José Carlos Martín, "Relatos hagiográficos sobre algunos obispos de la España medieval en traducción: Ildefonso y Julián de Toledo (BHL 3917 y 4554), Isidoro de Sevilla (BHL 4488) y Froilán de León (BHL 3180)”, Veleia, 28 (2011), pp. 220-224.

${ }^{21}$ Dentro de la abundante bibliografía sobre el manuscrito, caben destacar Ana Suárez González, "La biblia visigótica de la catedral de León (códice 6): primeros apuntes para un estudio arqueológico", Estudios Humanísticos. Historia, 10 (2011), pp. 179-196, y los dos trabajos de José Carlos Martín citados en la nota anterior.

22 Hasta la fecha, la descripción más pormenorizada del manuscrito la hallamos en Raimundo Rodríguez, "El códice 52 de la catedral de León y la liturgia", Archivos Leoneses, 6/11 (1952), pp. 103-107.

${ }^{23}$ Según consta en Cantus index, la pieza se asigna a las celebraciones de san Benito (Cantus ID 602079) y san Remaclo (Cantus ID 603110). Dentro de Le9, hallamos el canto completo en la celebración de san Isidoro; en su caso con el íncipit Sancte Isidore doctor (fol. 11). 
como comentábamos al inicio, son diferentes a las consignadas en $\mathrm{Lu}$, aspecto que abordaremos más adelante.

\section{LA COMPOSICIÓN POÉTICA}

Al igual que la mayoría de oficios rimados bajomedievales, los textos poéticos de san Froilán se adhieren a un esquema rítmico o acentual. En efecto, la acentuación, y no la cantidad silábica, se erige como elemento vertebrador de la versificación, tal como ocurre en la Antigüedad grecolatina y al comienzo de la Edad Media. Es precisamente esta subordinación al acento lo que deriva que estas composiciones sean también conocidas como oficios rítmicos. Lo primero que sorprende en nuestro oficio es la estabilidad de la cadencia acentual; como veremos, resultan excepcionales los versos híper o hipométricos. ${ }^{24}$ De igual modo, tampoco detectamos pasajes en prosa, lo que apunta a una composición relativamente tardía..$^{25}$

Distinguimos tres tipos de versos (véase Tabla 1). Siguiendo un orden de prelación descendente encontramos primero la estrofa goliárdica, advertible en 14 de los 28 cantos propios: las antífonas 1 a 8 de maitines y las 6 antífonas de laudes. A continuación tenemos el verso de 10 sílabas, observado en 13 piezas: la antífona $A d$ honorem patris, con la que se abren las primeras vísperas, la antífona de invitatorio Adsunt Froilani, los nueve responsorios de maitines, y las antífonas Pie pastor sanctae, última del rezo de maitines, y Salve sancte praesul, asociada al cántico de Magníficat de segundas vísperas. Finalmente, el dímetro yámbico es el modelo de versificación empleado en la antífona de Magníficat de primeras vísperas $O$ quanto desiderio. Los tres tipos de versos gozaron de amplia aceptación en la Edad Media, en particular el dímetro yámbico y la estrofa goliárdica. ${ }^{26}$

En detalle, la estrofa goliárdica consta de versos de 13 sílabas, divididos a su vez en dos hemistiquios: el

\footnotetext{
${ }^{24}$ Esa estabilidad en la cadencia acentual entraña cierto paralelismo con lo que sucede en la salmodia gregoriana. Sobre este particular, consúltese Terence Bailey, "Accentual and Cursive Cadences in Gregorian Psalmody", Journal of the American Musicological Society, 29/3 (1976), pp. 463-471.

25 La mezcla de secciones en poesía y prosa es un rasgo que distingue a los primeros oficios en verso; véase Wagner, Introduction to the Gregorian Melodies, pp. 264-265; y Hughes, "Late Medieval Plainchant", p. 55.

${ }^{26}$ Hughes, "Late Medieval Plainchant", p. 40. Reveladores, sobre este particular, son los datos expuestos por el musicólogo inglés para la composición de antífonas; véase Hughes, The Versified Office, p. 125.
}

primero de 7 sílabas con final proparoxítono y el segundo de 6 sílabas con terminación paroxítona $(7 \mathrm{pp}+6 \mathrm{p})$. Su cadencia declamatoria se basa en la alternancia de partes fuertes y débiles, aunque sin supeditarse a un patrón del todo estable. Es una forma métrica vinculada sobre todo a la poesía secular, más conocida por los célebres Carmina Burana. Su origen, no obstante, es religioso, pudiendo remontar su primer testimonio conservado al siglo IV: el estribillo Miserere domine / Christe miserere, una paráfrasis latina del Kyrie eleison obra del filósofo cristiano Mario Victorino. ${ }^{27}$

El verso de diez sílabas se compone también de dos unidades: a saber, un tetrasílabo paroxítono y un hexasílabo proparoxítono $(4 p+6 p p)$. Lo localizamos primeramente en dos himnos del siglo VII atribuidos a Beda el Venerable, ${ }^{28}$ pero no es hasta el siglo XI cuando logra una amplia aceptación. Además de en oficios rimados, fue bastante utilizado en secuencias, versus y dramas litúrgicos. ${ }^{29}$ De los tres metros poéticos transmitidos por el oficio, el de diez sílabas es el único que evidencia irregularidades en su versificación. Las hay de dos tipos: de extensión y de acentuación. Las primeras dan lugar a la localización puntual de líneas con un mayor o menor número de sílabas del que corresponde. ${ }^{30}$ Por su parte, las irregularidades en la acentuación provocan a veces el trocamiento del final proparoxítono en paroxítono; sucede, por ejemplo, en el responsorio Urbs non latet $\left(6^{\circ}\right.$ verso, "Flagrat ordo / vincens aromata"). Asimismo, localizamos muestras de segmentación anómala de los dos hemistiquios, bien por permuta entre sendas unidades o bien por alteración de las cantidades silábicas. ${ }^{31}$

${ }^{27}$ Hilkka-Lüsa Vuori, Marika Räsänen y Seppo Heikkinen, The Medieval Offices of Saint Thomas Aquinas, DocMus Research Publications, 14 (Helsinki: Sibelius Academy, University of the Arts, 2019), p. 113.

${ }^{28}$ Michael Lapidge, Bede's Latin Poetry, Oxford Medieval Texts, ed. J. W. Binns, D. d'Avray, M. S. Kempshall y R. C. Love (Oxford: Oxford University Press, 2019).

29 Hiley, Western Plainchant, p. 283.

${ }^{30}$ Hallamos muestras de versos hipermétricos en la antífona de invitatorio Adsunt Froilani ( $2^{\circ}$ verso, "Sancta mater / jubilet ecclesia") y el responsorio Aedificavit triplex (1 er verso, "Aedificavit / triplex coenobium"); de igual modo, advertimos versos hipométricos en el responsorio Exaltatur lucerna (3er verso, "Ut attendens / lumen mens tibi") y en la antífona Salve sancte praesul ( $2^{\circ}$ verso, "Vitae norma / via patriae").

${ }^{31}$ El primer caso lo divisamos en el responsorio Incombusti divina gratia, cuyo $5^{\circ}$ verso presenta un esquema de versificación $6 p+4 p p$ ("Summa peragentis / officia"); mientras tanto, el 
Por su parte, el dímetro yámbico es la forma más común de poesía litúrgica en la Edad Media. Consta de versos de ocho sílabas, divididos a su vez en dos pares de yambos, de los cuales el primero y el tercero pueden ser espondeos. Es un tipo de verso asociado sobre todo a los himnos, y no tanto a oficios en verso, razón que seguramente explique su presencia testimonial en el repertorio analizado. Otro aspecto a valorar es que el dímetro yámbico es una composición más métrica que rítmica, de ahí que la posición del acento no sea regular, ${ }^{32}$ aspecto corroborado en la antífona $O$ quanto desiderio.

Posiblemente una de las peculiaridades más remarcables de la composición poética sea la ausencia de unidad métrica, rasgo asociado a los oficios más antiguos. ${ }^{33}$ Dicha ausencia condiciona que la longitud de las poesías sea fluctuante. El escenario más extremo lo hallamos en las antífonas, donde la extensión de dos versos suele ser la norma, aunque en momentos puntuales alcanzan los seis y ocho versos. Las composiciones más largas coinciden por lo general con las antífonas ad evangelia (Magníficat y Benedictus), lo que no quita que haya excepciones: Ad honorem patris y Pie pastor sanctae contabilizan seis versos y no por ello anclan su interpretación a los referidos cánticos evangélicos. El pico máximo de ocho versos lo divisamos, mientras tanto, en $O$ quanto desiderio. En su caso, es obvio pensar que esa mayor extensión responda a su adscripción al dímetro yámbico, la forma poética con menor número de sílabas por verso de las tres utilizadas en el oficio. Por su parte, los responsorios constan de cinco o seis versos, salvo Incombusti divina gratia que suma hasta siete versos.

La identidad poética se pone de manifiesto a partir del uso de versos de rima bisilábica. Las excepciones dentro del oficio son muy contadas, ${ }^{34}$ lo que es sintomático del esmero con el que han sido elaborados sus textos. Lo primordial en la versificación es que los sonidos vocálicos, y no tanto los consonánticos, sean coincidentes tras la última sílaba acentuada. Ello genera una

\footnotetext{
segundo escenario se aprecia en el responsorio Constitutus in pueritia, con una distribución $3+7 \mathrm{pp}$ en su $4^{\circ}$ verso ("Per hunc quod / promantur eulogia").

${ }^{32}$ Hiley, Western Plainchant, p. 281.

33 Wagner, Introduction to the Gregorian Melodies, pp. 264 y 269. Esta mezcla de diferentes métricas es un aspecto censurado por el musicólogo alemán; véase Wagner, Introduction to the Gregorian Melodies, p. 269.

${ }^{34}$ Nos referimos a los responsorios Exaltatur lucerna $\left(6^{\circ}\right.$ verso, "tibi") y Urbs non latet ( $6^{\circ}$ verso, "aromata"), con conclusiones anómalas conforme al patrón de rima.
}

equilibrada alternancia entre versos de rima consonante y asonante, predominando los primeros sobre todo en las antífonas. ${ }^{35}$ Sin duda este es un hecho a destacar, dada la asociación de la rima asonante con los oficios en verso más antiguos. ${ }^{36}$ De forma abrumadora la rima es además continua. Las únicas excepciones las hallamos, primero, en el responsorio Sancti patris nos juvent y en la antífona Pie pastor sanctae, con patrón de rima gemela; segundo, en el responsorio Benedicti professus con esquema $\mathrm{AAABB}$, correspondiendo A con el cuerpo del responsorio y $\mathrm{B}$ con el versículo; y tercero, en las antífonas $O$ quanto desiderio y $O$ lumen spectabile, donde la rima es cruzada. En relación al último canto, vale la pena notar que la alternancia se produce, no entre versos seguidos, sino entre hemistiquios de un mismo verso, siendo la única composición en estrofa goliárdica en la que se da este fenómeno.

Atendiendo a su temática, cabría clasificar los poemas en dos grandes grupos: los de naturaleza panegírica, predominantes sobre todo en los responsorios y las antífonas ad evangelia, y los narrativos, más vinculados con las antífonas menores, aunque con muestras también entre los responsorios (Constitutus in pueritia y Aedificavit triplex). Los primeros no parece que beban de ninguna fuente literaria, al menos en lo que hemos podido rastrear; tal hecho no excluye, sin embargo, la localización de expresiones convencionales, tipo "audi devotas preces hodie" ("atiende en este día nuestras devotas súplicas"), advertible en la antífona Salve sancte praesul. Las antífonas de maitines y laudes son las que, en mayor grado, glosan el relato de la Vita Froilanis, si bien de manera muy libre y condensada a fin de facilitar su acomodo poético. Las alusiones literales son inexistentes y sólo tímidamente podemos verificar el procedimiento de paráfrasis. La muestra más clara la tenemos en la antífona Natus in suburbio, con una redacción bastante dependiente del inicio de la Vita; véase Tabla 2:

\footnotetext{
${ }^{35}$ Merece la pena señalar, sobre este particular, que todas las antífonas de laudes son de rima consonante. Entre los responsorios, similar planteamiento sólo lo hemos podido advertir en Benedicti professus.

36 Wagner, Introduction to the Gregorian Melodies, pp. 264265; y Hughes, The Versified Office, p. 59.
} 


\begin{tabular}{|l|l|}
\hline \multicolumn{1}{|c|}{ Texto de la antífona } & \multicolumn{1}{c|}{ Vita Froilanis } \\
\hline $\begin{array}{l}\text { Natus in suburbio / Luci disciplinam } \\
\text { amplexatur precavens / mortalem ruinam. }\end{array}$ & $\begin{array}{l}\text { Fuit uir uite uenerabilis Froianus aepiscopus in } \\
\text { subhurbium Lucense hortus ciues Gallecie, ab infantia } \\
\text { in sanctis disciplinis eruditus, timens Deum et recedens } \\
\text { a malo. }{ }^{37}\end{array}$ \\
\hline
\end{tabular}

Tabla 2. Correlación entre la antífona Natus in suburbio y el inicio de la Vita Froilanis.

Este grupo de piezas narrativas juega además un papel esencial en el oficio, pues son las que, de algún modo, completan el relato de las lecciones históricas, interrumpido en $\mathrm{Lu}$ tras la fundación del primer monasterio. ${ }^{38}$ Gracias a ellas sabemos de la construcción de más cenobios (responsorio Aedificavit triplex), la predicción de su muerte y acontecimientos futuros (antífonas Patiens et humilis, Spiritus edocuit y De salute populi) o su rechazo inicial a aceptar la dignidad de obispo (antífona Invitus assumitur).

Las antífonas de maitines constituyen un ciclo narrativo por sí mismo, con mención de los principales episodios de la vida del santo en orden cronológico: su nacimiento y primera educación (Natus in suburbio y Concupivit heremum), los testimonios de santidad, con especial énfasis en la serie de milagros (Prunas cultor, Froilanus prospicit, Varias vir optimus y Os columba rubea) y, finalmente, el anuncio de su muerte (Patiens et humilis y Spiritus edocuit). La antífona novena Pie pastor sanctae, de naturaleza laudatoria, proporciona una conclusión satisfactoria a los hechos relatados, momento en que se subraya el papel de Froilán como intercesor ante Dios. Las antífonas de laudes muestran también una cierta interrelación, aunque más débil e inconsistente. Refieren a grandes rasgos las virtudes cristianas del santo, proyectadas a partir de su labor de predicación y atención espiritual al pueblo. Al igual que en maitines, el ciclo de laudes concluye con una antífona de tono panegírico ( $O$ lumen spectabile), donde se ensalza la santidad de Froilán.

Esa orientación predominantemente narrativa de las antífonas provoca, a la postre, la ausencia de alusiones al salmo o cántico con el que van coaligados, rasgo habitual en el canto gregoriano. En su lugar, asumen un cometido más asociado a los responsorios. En efecto, son éstos, y no las antífonas, quienes tradicionalmente se encargan de

\footnotetext{
${ }^{37}$ Reproducimos la edición crítica proporcionada por Martín, "La Vita Froilanis", p. 578.

38 Aspecto ya constatado por López Peláez, Vida póstuma, p. 163 , aunque sin establecer esa doble división entre textos panegíricos y narrativos.
}

glosar las biografías de santos como resultado del vínculo que establecen con las lecciones históricas. ${ }^{39}$ Dicha alianza hace frecuente que los responsorios resuman el contenido de las lecciones, hasta el punto incluso de repetir sus partes más esenciales. ${ }^{40}$ Ese escenario, sin embargo, no se verifica en el repertorio estudiado, donde es patente la independencia entre ambas secciones. La razón de ello seguramente haya que buscarla en su flexible aplicación litúrgica: a diferencia de las lecciones, que son individualizadas, los cantos se entonaban en ambas celebraciones del santo: el die obitus en octubre y la traslación de las reliquias en agosto. Más chocante aún si cabe es la completa ausencia de referencias a la Biblia o a los Santos Padres en todo el oficio, factor que determinaría su posterior remoción de la liturgia una vez oficializado el rezo tridentino. ${ }^{41}$

Haciendo balance, es claro el propósito de construir la santidad de Froilán a partir de tres imágenes interconectadas: la exaltación de sus cualidades morales, espirituales y taumatúrgicas, hecho que dota al relato de un cierto aire de etopeya; la observancia de una férrea disciplina monástica, adquirida inicialmente en su deambular por páramos desiertos y proyectada después en una destacada labor fundacional; y finalmente, su intensa actividad predicadora entre el pueblo. Con el fin de procurar su mejor cohesión, la composición hace uso recurrente de conceptos clave a modo de motivos conductores. Las virtudes de orden espiritual se subrayan a partir de adjetivos tales como santo, humilde, dócil, paciente o piadoso. Entretanto, su condición de monje ermitaño queda de relieve

${ }^{39}$ Hughes, "Rhymed Offices", p. 368.

${ }^{40}$ Michel Huglo, Les livres de chant liturgique, Typologie des sources du Moyen Âge occidental, 52 (Turnhout: Brepols, 1988), p. 26.

${ }^{41}$ Esa base no escriturística, unido a la inclusión de abundantes elementos de dudable fiabilidad histórica, no impidió que el oficio se mantuviera vigente en la catedral leonesa durante bastante tiempo. No es, de hecho, hasta 1682 cuando el cabildo aprobó su sustitución por otro nuevo; véase Taurino Burón Castro, "El Cabildo de la Catedral, impulsor del culto de san Froilán", Studium Legionense, 47 (2006), pp. 283-285, especialmente la n. 10. 
en las numerosas alusiones a la montaña, la observancia interior y la vida monacal. De especial valor aquí son sendas menciones a la condición benedictina de Froilán; las podemos localizar en la antífona $O$ quanto desiderio $\left(5^{\circ}\right.$ verso, "Benedicti religio") y en el responsorio Benedicti professus (inicio). Lo interesante es que esa información no es transmitida por la Vita, y por la rotundidad con que se declara, hipotetiza una posible paternidad benedictina de los textos poéticos. Por último, la labor evangelizadora de Froilán se proyecta en forma de abundantes referencias a sus enseñanzas entre el pueblo. Aun en corto número, encontramos también algunas alusiones a lugares y personajes. Entre los primeros, su nacimiento en Lugo (antífona Natus in suburbio), su condición de obispo de León (antífona $O$ quanto desiderio) y el monte Curueño, donde hizo vida solitaria (antífona Os columba rubea); ${ }^{42}$ en cuanto a los segundos, cabe destacar la antífona Spiritus edocuit, en la que se identifica a Froilán con el profeta Jeremías por su don de presagiar el futuro.

Es ostensible asimismo la voluntad de ensalzar el mensaje ético a expensas de artificios técnicos. La composición poética resulta cuidada en extremo, empleando un lenguaje sencillo a fin de infundir sentimientos de devoción entre los fieles. Lo interesante aquí es que esa sencillez no está reñida con la utilización de un léxico bastante variado. El mejor exponente de ello lo tenemos en la prolijidad de expresiones sinonímicas con las que se refiere a Froilán; entre ellas, santo, pastor, padre, patrón, pontífice u obispo. El lenguaje metafórico se hace igualmente presente a partir de la contraposición de la luz y la oscuridad, motivos centrales de los responsorios Devergente jam solis radio y, sobre todo, Urbs non latet.

Todos los indicios hasta aquí reunidos demuestran la buena formación latina del autor o autores de la composición poética. La planificación resulta en todo momento cuidada, combinando de forma bastante equilibrada textos de carácter panegírico con biográficos: los primeros hacen amplio uso de tópicos habituales del género hagiográfico, en tanto que los segundos se inspiran de manera libre en la redacción de la Vita Froilanis. Todo apunta además a que se trate de una redacción en buena medida original, afirmación sobre la que conviene guardar cautela dado el conocimiento desigual que se tiene de los oficios litúrgicos en verso. Por último, ha quedado

\footnotetext{
${ }^{42}$ Como dato llamativo, la mención al monte Curueño $(\mathrm{Cu}-$ currinum en latín) no es explícita, sino que se inserta en un contexto en el que se alude al arrullo de las palomas ("sed demulcet leniter alba quae cucurrit").
}

patente la orientación moralizante de los textos, hecho constatable a partir del empleo de un lenguaje sencillo a la par que comprensible.

\section{ESTRUCTURAS MODALES Y POÉTICAS}

El primer aspecto que conviene aclarar es que las musicalizaciones del oficio de san Froilán en Lu y Le9 parten de premisas distintas. A diferencia del primero, Le9 toma como base melodías preexistentes del Común de santos. A falta de mayores certezas, pensamos que en el ánimo de sus compiladores estuvo reutilizar preferentemente composiciones ligadas a la liturgia de un confesor, grupo al que se adscribe Froilán. El alto índice de transferencias musicales entre las celebraciones del Santoral, unido al limitado número de melodías editadas hasta la fecha impiden extraer mayores conclusiones. Antes de proseguir, debemos puntualizar que el análisis comparativo se apoya en el uso de la herramienta digital de búsqueda por melodías proporcionada por la web de Cantus Database. ${ }^{43}$

Los cantos en Le9 se elaboran a partir del procedimiento de contrafactum, si bien con un grado disímil de correlación melódica. En los responsorios Devergente jam solis radio y Benedicti professus el paralelismo es notorio. El primero de ellos toma como modelo el responsorio Qui sunt isti qui ut nubes, asignado a las celebraciones de apóstoles y Todos los santos. Por su parte, Benedicti professus reproduce de manera bastante fiel la melodía del responsorio Vos estis lux mundi, vinculado también a las fiestas de apóstoles. En lo tocante a Exaltatur lucerna, creemos que su matriz puede estar en el responsorio Iste sanctus digne, del Común de un confesor; si bien, huelga señalar que el paralelismo melódico no resulta aquí tan evidente.

La única pieza en la que no hemos logrado establecer ningún parentesco melódico en Le9 es el responsorio Constitutus in pueritia, adscrita al modo IV; véase Figura 1. No parece, de todas formas, que se trate de una melodía de nueva creación, pues su desarrollo se adhiere a unas coordenadas eminentemente gregorianas. El ámbito vocal se restringe a la $7^{\mathrm{a}} \mathrm{DO}-\mathrm{SI}$ : el DO, como término grave, sirve de apoyo en los ascensos al agudo ("ad montis"), mientras que el SI actúa siempre de adorno a LA ("detestatur") o SOL ("invia"). Encontramos, asimismo, cuerdas de recitación bastante definidas, bien sobre FA ("in pueritia") o sobre MI ("devotorum sunt"). En general, la música desprende un claro sabor

${ }^{43}$ Cantus: A Database for Latin Ecclesiastical Chant. Search by melody, <http://cantus.uwaterloo.ca/melody $>$ [consulta: 24/10/20].

ANUARIO MUSICAL, N. ${ }^{\circ} 76$, enero-diciembre 2021, 31-49. ISSN: 0211-3538 https://doi.org/10.3989/anuariomusical.2021.76.03 

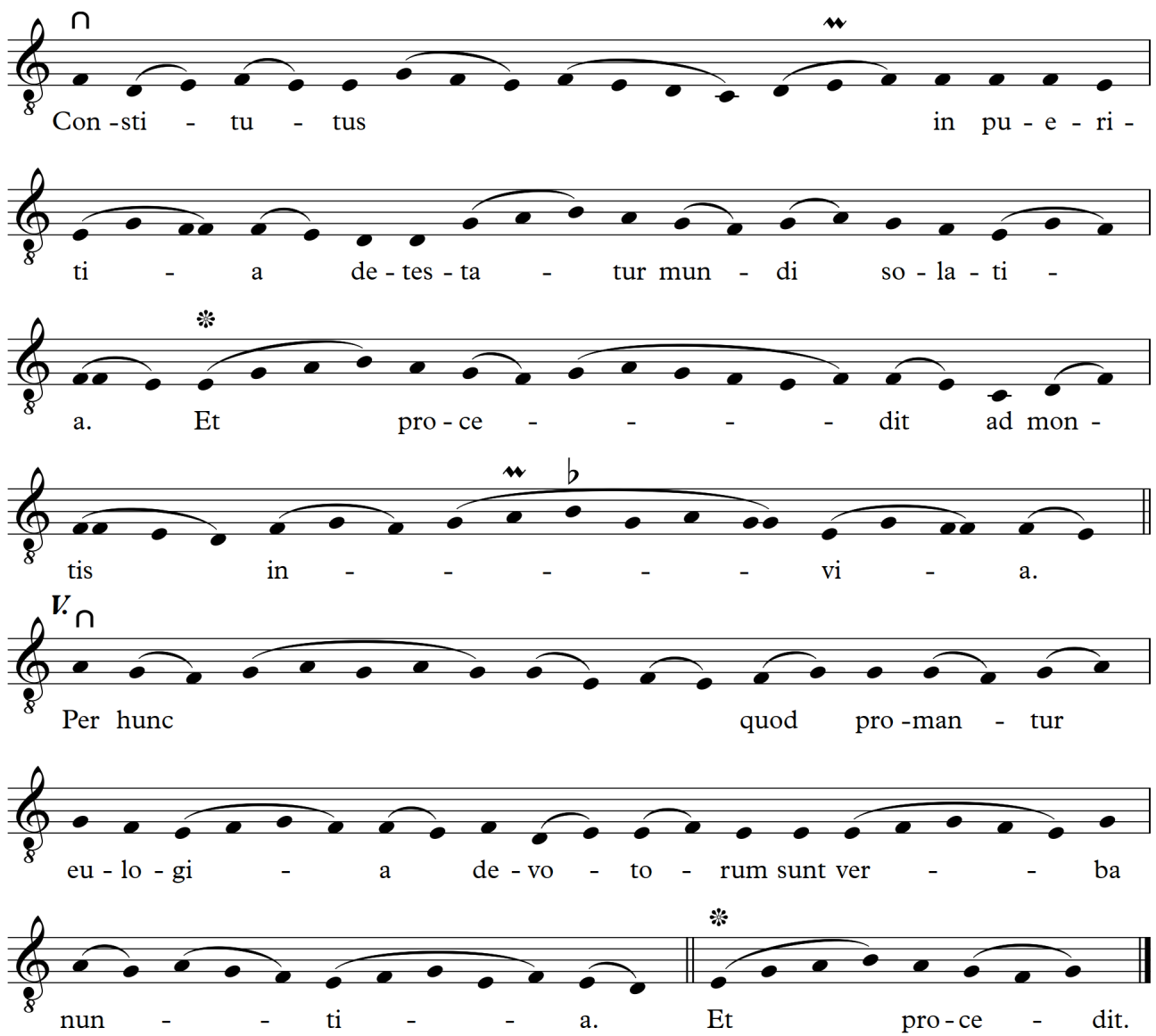

Figura 1. Versión del responsorio Constitutus in pueritia en Le9.

Signos empleados en las transcripciones musicales:

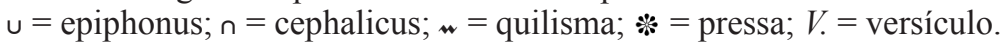

formulario, con melodías-centones acordes a la estética del deuterus plagal, como la entonación MI-SOL-LA ("Et procedit") o las cadencias adornadas sobre MI ("pueritia", "solatia" e "invia"). También es interesante comprobar cómo el movimiento melódico en ningún caso se subordina a la posición del acento; y en modo paralelo, cómo el versículo de responsorio, en vez de ser de nueva creación, parafrasea una conocida melodía-tipo asociada al modo IV.

La sintaxis musical del oficio en Lu discurre por derroteros bien distintos. En general pensamos que se trata de composiciones de nueva creación, aunque es una apreciación sobre la que hay que guardar cierta cautela a la espera de contar con un estudio sistemático de la composición ibérica de canto llano en la Baja Edad Media. De lo que no cabe duda es que responde a una concepción mucho más moderna, si bien, y esto es importante remarcarlo, claramente deudora todavía de la tradición ancestral. Los cambios, por descontado numerosos, no suelen ir más allá de meros retoques secundarios. En buena medida pueden reducirse a dos fenómenos: primero, la sujeción a un marco organizativo más férreo y en parte predecible; y, segundo, el incremento del dinamismo melódico, el cual, como contrapartida, provoca la práctica desaparición de las recitaciones recto tono. En contraste con la moderación de antaño, el artificio juega un papel importante en estas composiciones, haciéndolas si cabe más melodiosas auralmente. Esa exuberancia sonora no entraña además menoscabo alguno en la proclamación de la palabra, seña principal y fundante del canto litúrgico. Lo que sí es apreciable es una creciente orientación de la línea melódica hacia el acento prosódico, sin llegar a las rigideces que caracterizan al canto llano postridentino. 
Uno de los primeros aspectos que llama la atención en la redacción musical de Lu es el orden correlativo de modos suscrito por las antífonas. Distinguimos dos ciclos (Tabla 1): maitines, que hace el recorrido completo del modo I al VIII repitiendo a continuación el modo I; y laudes, cuya secuencia discurre desde el modo I al VI. Como tal, es un tipo de ordenamiento bastante habitual en la composición tardomedieval, que cuenta con precedentes destacados, como el oficio de la Santísima Trinidad atribuido al obispo Esteban de Lieja $(† 920),{ }^{44}$ o, ya más específico del ámbito hispano, el repertorio monódico del Códice Calixtino ${ }^{45}$ Es una práctica además que perduró más allá de Trento, si bien contamos con indicios que muestran la introducción de alguna leve alteración para no hacer el ciclo completo gradatim. ${ }^{46}$ La composición por orden de tonos obedece fundamentalmente al deseo de sistematizar la composición gregoriana conforme a las leyes del Octoechos. En lo que es específico de las antífonas, ese ordenamiento busca evitar también una excesiva reiteración de una misma fórmula de recitación salmódica. Acerca del mismo, Huglo sostiene que seguramente su desarrollo estuvo influenciado por los tonarios, sin descartar la paternidad de algún compositor-teórico. ${ }^{47}$

Que los responsorios no hagan gala de un ordenamiento de semejantes características entra dentro de lo esperable. Su naturaleza melismática unido al hecho de no anclar su entonación a la recitación de salmos les confería una mayor libertad compositiva. De hecho, ni siquiera los

${ }^{44}$ Hughes, "Late Medieval Plainchant", pp. 45-47; Gunilla Björkvall y Andreas Haug, "Performing Latin Verse. Text and Music in Early Medieval Versified Offices", en The Divine Office in the Latin Middle Ages. Methodology and Source Studies, Regional Developments, Hagiography, ed. Margot E. Fassler y Rebecca A. Baltzer (Oxford: Oxford University Press, 2000), pp. 278-286.

45 Francisco Javier Lara Lara, "Estructuras modales en el Códice Calixtino", en El Códice Calixtino y la música de su tiempo. Actas del simposio organizado por la Fundación Pedro Barrié de la Maza en A Coruña y Santiago de Compostela, 20 - 23 de septiembre de 1999 (A Coruña: Fundación Pedro Barrié de la Maza, 2001), p. 274.

46 Así sucede en la colección de libros de coro de la catedral de Segovia; véase Santiago Ruiz Torres, "La monodia litúrgica entre los siglos XV y XIX. Tradición, transmisión y praxis musical a través del estudio de los libros de coro de la catedral de Segovia", tesis doctoral, Universidad Complutense de Madrid, 2013, p. 334.

${ }^{47}$ Michel Huglo, Les tonaires: inventaire, analyse, comparaison (Paris: Université de Paris, 1971), pp. 122-123. versículos de responsorio emplean alguna de las melodíastipo preexistentes. Todas sin excepción han sido compuestas ex novo, circunstancia, sea dicho de paso, bastante habitual en los oficios tardomedievales. Hay que valorar, asimismo, que la composición en orden serial se asociaba sobre todo a textos biográficos, aspecto no corroborado en los responsorios objeto de estudio, de claro tono laudatorio.

Uno de los datos más relevantes que se desprenden del análisis es el papel crucial que juega el texto en la elección modal. Tal hecho revela la familiaridad de su compositor con la doctrina del ethos. A lo largo de la Edad Media fueron muchos los teóricos que atribuyeron distintas cualidades a los modos, aportando descripciones muchas veces carentes de consistencia y sujetas a múltiples vaivenes según el tiempo. Por esa razón, tomamos como referencia la clasificación modal propuesta por Jeanneteau, la cual conjuga las consideraciones de los compositores-teóricos del Medievo con el necesario análisis del repertorio. Según la misma, los modos I y II expresan sentimientos de ternura y contención; los modos III y IV presentan un carácter místico y contemplativo; los modos V y VI irradian alegría; y los modos VII y VIII mueven a la contemplación de las cosas celestiales. ${ }^{48}$ Ese carácter ético consustancial a la modalidad gregoriana proporciona, a la postre, una valiosa ayuda a la hora de incrementar la eficacia del relato hagiográfico. De esta forma, los datos de naturaleza biográfica se vinculan en el oficio con los modos I y II, los hechos violentos y misteriosos al deuterus, los milagros tanto al deuterus como al tritus, y las premoniciones en el lecho de muerte al tetrardus. La ordenación correlativa de modos, tal como sucede en las antífonas de maitines, contribuye en suma a construir la personalidad, vida y acciones del santo dentro de la liturgia. Así, el carácter cambiante de su historia se ve reflejado a través de modos cambiantes. La repetición del modo I en la novena antífona no hace más que reforzar el marco organizativo del Octoechos, proporcionando una conclusión satisfactoria. Haciendo balance, el protus auténtico es el registro modal que acapara cifras más altas de composición (10 de los 28 cantos propios), lo que es sintomático de su estatus privilegiado. El polo opuesto lo encontramos en los modos VII y VIII, apenas representados (un canto por cada modo) y ello a pesar del notable arraigo del que gozan en el estrato gregoriano más primitivo. ${ }^{49}$

48 Jean Jeanneteau, Los modos gregorianos. Historia, análisis, estética, Studia Silensia, 11 (Silos: Abadía, 1985).

${ }^{49}$ Ese declive de los modos de SOL es común en el reper- 
Lo dicho hasta aquí pone de relieve la capacidad que demuestra el compositor del oficio para conjugar un artificio técnico, como es la composición en orden de modos, con un absoluto respeto a la cualidad ética del texto. No es infrecuente en la época que la primacía de la palabra sea socavada en favor de otras consideraciones ajenas a la sintaxis gregoriana, aspecto censurado por algunos teóricos. ${ }^{50}$

La tesitura de los cantos entra dentro de las coordenadas de moderación que caracterizan al corpus gregoriano más antiguo. Todas las piezas, salvo cuatro, sitúan su ámbito vocal entre la octava y la novena. Las excepciones las encontramos, por un lado, en las antífonas $\mathrm{Ad}$ sunt Froilani y De salute populi, donde la interválica se restringe a la séptima; y por otro, en el responsorio Exaltatur lucerna y la antífona $O$ summe spectabile, que la extienden hasta la décima y la undécima respectivamente. Pese a ello, no representan tesituras muy extremas para un repertorio, como el de los oficios rimados, acostumbrado a alcanzar la doceava o más. ${ }^{51}$ En ambos casos ese amplio rango vocal provoca la amalgama de los registros auténtico y plagal. Semejante comportamiento no sorprende tanto en el responsorio Exaltatur lucerna, cuya asignación al protus mixto es compartida por numerosas piezas gregorianas; ${ }^{52}$ pero sí en la antífona $O$ summe spectabile, donde resulta más inusitada la sonoridad de tritus mixto. La mixtura modal no es, con todo, un rasgo exclusivo de las piezas que acreditan una tesitura amplia. Por un lado, los cantos en modo VI, y en menor medida los de modo II, destacan por un acusado desarrollo del agudo. ${ }^{53}$ Asimismo, resulta llamativo el relieve que adquiere el RE grave en el repertorio en modo III, lo que da pie a conducciones melódicas emparentadas con los modos I ("cladem pestilentiae" en la antífona De salute populi) y VIII ("sunt illaesa labia" en la antífona Prunas cultor).

torio litúrgico en verso; véase Hughes, The Versified Office, pp. 238-239.

50 Sobre este particular, guarda interés la consulta del Tractatus de Tonis (ca. 1300) de Guy de Saint-Denis; Constant J. Mews, Carol J. Williams, John N. Crossley y Catherine Jeffreys, Guy of Saint-Denis, Tractatus de tonis (Kalamazoo: Medieval Institute Publications, 2017).

51 Hughes, "Rhymed Offices", p. 375.

52 Jeanneteau, Los modos gregorianos, p. 90.

53 Salvo la antífona Os columba rubea, todo el repertorio en tritus plagal alcanza el RE agudo, un grado fuera de su ámbito natural. Por su parte, el LA agudo cobra un inusitado realce en muchas piezas en protus plagal; sirva de ejemplo el segundo verso de la antífona Contemplatur jugiter.
El discurso melódico se caracteriza por una marcada linealidad, sustentada en abundantes fórmulas escalares, y no tanto en movimientos circulares a semejanza del gregoriano primitivo. En particular, resultan especialmente numerosas las conducciones por grados conjuntos en interválicas de cuarta; así, por ejemplo, el responsorio Sancti patris nos juvent ("ipsius juvemur", Figura 2), de perfil bastante sinuoso merced a las sucesivas subidas y bajadas. Los saltos directos son infrecuentes y, de producirse, suelen asociarse a patrones recurrentes de algún modo del Octoechos. Más inusual en el lenguaje gregoriano son sendos saltos directos por sexta, verificables en el responsorio Exaltatur lucerna ("domus lucida" y "trahit ad", Figura 6). ${ }^{54}$ Ese alto dinamismo melódico trae consigo la práctica desaparición de las recitaciones recto tono, una de las señas distintivas del corpus más antiguo. Es más, las pocas muestras localizadas quedan literalmente sepultadas por una tupida ornamentación, como sucede en el versículo del responsorio Sancti patris nos juvent ("nobis detur corona", Figura 3). Otra de las consecuencias aparejadas a esta evolución es la completa ausencia de melodías-tipo en el repertorio, lo cual trasluce un cierto afán compositivo. Creemos que este cambio de criterio estético responde en buena medida al debilitamiento de la tradición oral, hecho acaecido sobre todo a partir del siglo XIII. La transmisión de las melodías gregorianas, antes confiada a la memoria, devino fundamentalmente en acto "a la vista". ${ }^{55}$ El apoyo regular de los libros estimuló, a la larga, la inventiva de los compositores, haciéndoles menos dependientes de esquemas predefinidos tal como sucedía antaño.

Algo bien distinto ocurre con las melodías-centones, de aparición bastante asidua en la composición posgregoriana. Aparte de las fórmulas cadenciales y de entonación, que analizaremos más adelante, los motivosenlace cobran bastante protagonismo en el oficio por su función de interconexión fraseológica. Uno muy asiduo en el repertorio es la secuencia hacia el agudo LA-DO$\mathrm{RE}$, localizada en cantos en los modos I y VI. Su misión es la de servir de arranque melódico tras el reposo cadencial, por lo general desde la finalis ${ }^{56}$ pero sin descartar

\footnotetext{
${ }^{54}$ Analizamos la pieza más adelante con mayor detenimiento, de ahí que la numeración de figuras no discurra de manera correlativa.

${ }_{55}$ Huglo, Les livres de chant, p. 50.

${ }^{56}$ El arranque desde el RE grave es advertible en las antífonas de modo I Ad honorem patris ("novi sonent" y "quem laudantes"), Pie pastor sanctae ("comprimantur") e In amore
} 


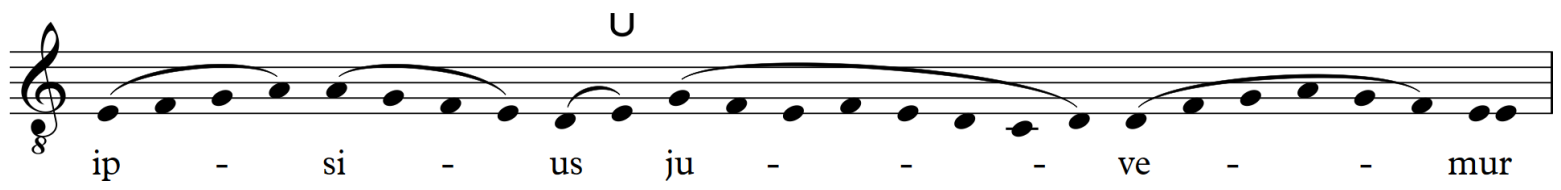

Figura 2. Responsorio Sancti patris nos juvent (extracto).
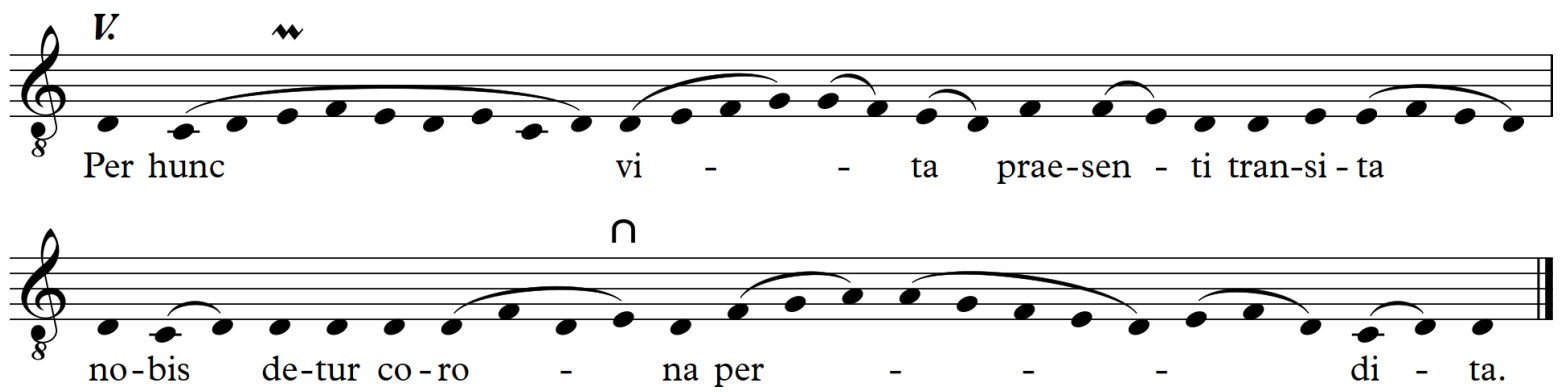

Figura 3. Responsorio Sancti patris nos juvent (versículo).

otros grados estructuralmente importantes en la arquitectura modal. ${ }^{57}$ Dicho motivo es objeto a veces de transformación a partir de la adición de notas de relleno. ${ }^{58}$

Detrás de todas estas innovaciones se intuye el deseo de conferir mayor atractivo melódico al canto sacro en consonancia con lo que ocurre en otros repertorios poéticos coetáneos, en particular tropos y secuencias. Esa creciente direccionalidad melódica es precisamente uno de los rasgos que distingue a los oficios en verso tardomedievales, ${ }^{59}$ y al parecer también a los de origen ibérico. ${ }^{60}$

El hecho de sustentar la trama musical sobre poesía rítmica provoca que las frases se tornen más regu-

jugiter ("fundat et constituit"; véase Figura 4). Por su parte, el ascenso desde FA se observa en la antífona de modo VI $O$ quanto desiderio ("exsultans colit").

57 En el responsorio de modo I Opem nobis benigne la fórmula parte desde la dominante salmódica LA ("rege stantes").

58 Así, por ejemplo, la subida LA-RE agudo por grados conjuntos, perceptible en el responsorio Aedificavit triplex ("post reccesum"), o la solución levemente adornada que apreciamos en el responsorio Urbs non latet ("ad montis abdita").

59 Hughes, "Late Medieval Plainchant", p. 67; y Hughes, The Versified Office, pp. 266-268.

${ }^{60}$ Las melodías hasta hoy editadas para los oficios de la traslación de san Vicente y Santiago apóstol reflejan un comportamiento análogo; véase Ferreira, "The Lisbon Office", pp. 83-86; y Ruiz Torres, "El oficio de la Traslación”, pp. 85-87. lares, cada una de ellas articulada por figuras cadenciales bien definidas. La fluidez melódica de antaño se sacrifica parcialmente en favor de una conducción más segmentada que, en ocasiones, parece discurrir por palabras sueltas. Las características apuntadas resultan evidentes sobre todo en las antífonas, en particular las de naturaleza más simple. Es en ellas donde más fácilmente se puede advertir la estructura poética. El tipo de métrica juega un papel importante en todo este proceso. Así, cuanto menor es la prolongación de los versos, más acusada resulta la sensación de compartimentación. Un exponente destacado de ello lo tenemos en la antífona de Magníficat $O$ quanto desiderio, cuya adscripción al dímetro yámbico le confiere una sonoridad cuasi hímnica. Visto desde esta óptica, parece razonable pensar que la elección mayoritaria del metro goliárdico en las antífonas obedezca al deseo de distinguir su composición de la de los himnos. Sus versos más extensos $(7 p p+6 p)$ generan una sonoridad a caballo entre poesía y prosa, la cual bien identifica a este grupo de piezas. Esa concepción segmentada de las antífonas favorece además que presenten una arquitectura sonora más definida. Muchas de estas piezas hacen uso de una estructura en arco, caracterizada por un inicio en tónica, subida fundamentalmente por grados conjuntos hacia el agudo y retorno a la tónica por similares medios. Dichas cualidades se ponen de manifiesto especialmente en las antífonas de laudes; véase, por ejemplo, In amore jugiter (Figura 4). 

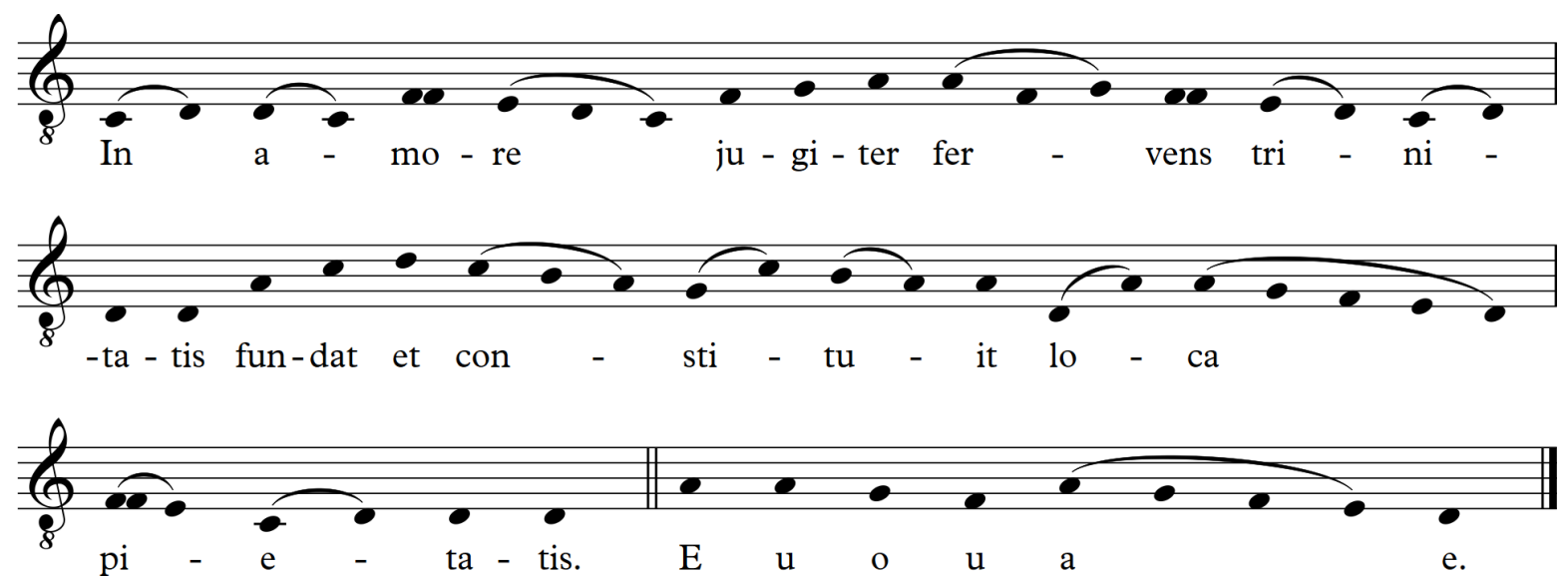

Figura 4. Antífona In amore jugiter.
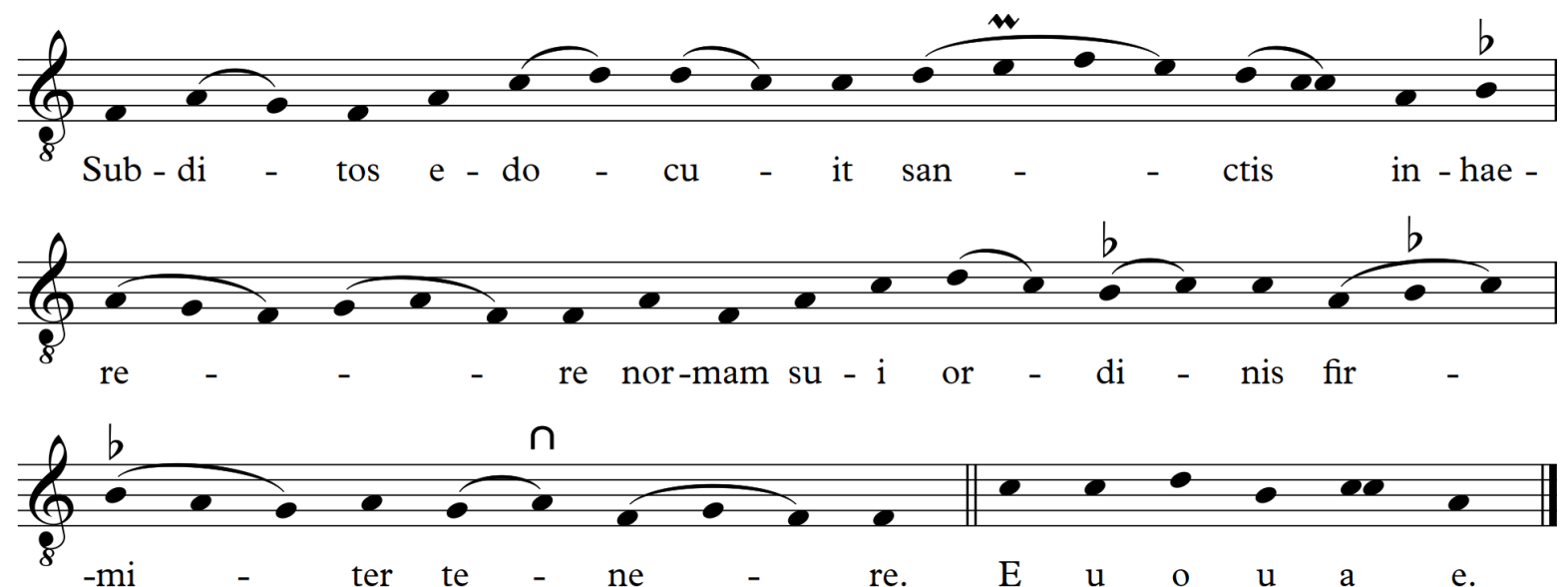

Figura 5. Antífona Subditos edocuit.

Otra de las consecuencias derivadas de la regularización fraseológica en las antífonas es la adopción de estructuras bipartitas de pregunta-respuesta. Ese juego de alternancia puede producirse bien entre los hemistiquios de un mismo verso, o bien entre versos distintos. El primer escenario lo contemplamos en la antífona de laudes Subditos edocuit en modo V; véase Figura 5. Como tal, consta de dos frases musicales, siendo la segunda una leve variación de la primera. Por su parte, la dialéctica de pregunta-respuesta entre versos distintos queda de manifiesto sobre todo en la antífona $\mathrm{Ad}$ honorem patris, en modo I. La misma comprende un total de seis periodos en disposición $\mathrm{ABABAB}$, concluyendo la primera parte en la dominante LA y la segunda en la finalis RE.

Con carácter general las innovaciones musicales comentadas apenas se aprecian en los responsorios, don- de el mayor grado de densidad melódica atenúa la percepción de simetrías. Estas, de hecho, resultan solo evidentes en casos de clara repetición melódica, muy pocas en cómputos globales. Sirva de muestra el versículo del responsorio Exaltatur lucerna, cuyos dos hemistiquios reproducen una melodía similar con pequeñas variantes; véase Figura 6.

Las cadencias musicales constituyen un punto sobre el que hay que prestar especial atención en los oficios poéticos por su correlación con la rima textual. A diferencia de lo que sucede en el corpus primitivo, estos reposos coinciden de forma abrumadora con los grados estructuralmente más importantes del armazón modal. Los datos no pueden ser más elocuentes: del total de 108 cadencias contabilizadas, 79 se corresponden con la finalis, 18 con el tenor salmódi- 

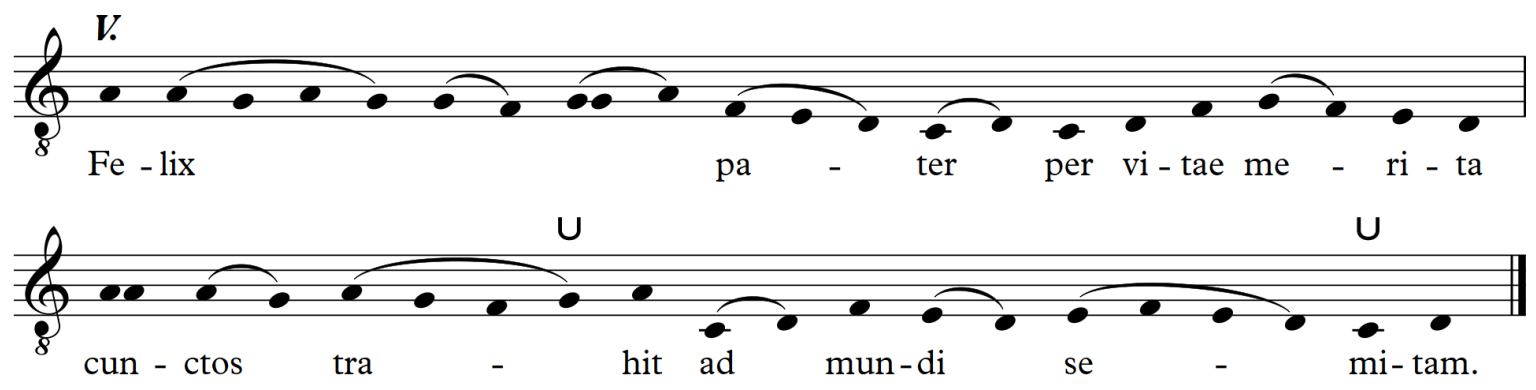

Figura 6. Responsorio Exaltatur lucerna (versículo).

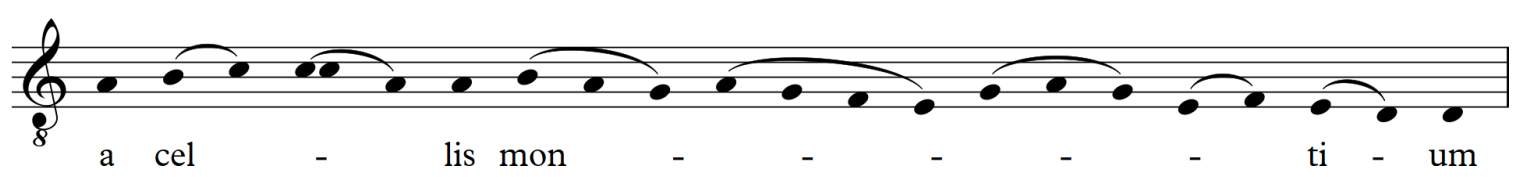

Figura 7. Responsorio Aedificavit triplex (extracto).

co y las 11 restantes se producen en notas distintas. Vale la pena señalar que, dentro de este último grupo, hallamos 5 casos en donde la terminación acontece sobre la dominante del compañero plagal o auténtico, lo que es indicativo de una cierta mixtura modal. Esta sobreabundancia de la nota finalis en los movimientos cadenciales bien justifica la célebre cita de Guido d'Arezzo († 1050) "in fine judicabis", esto es, al final juzgarás. Es la conclusión del canto y las secciones intermedias las que permiten averiguar el modo, y no tanto otros procedimientos más vinculados con el gregoriano temprano, como las entonaciones melódicas y las cuerdas fundamentales. ${ }^{61}$

Las figuras cadenciales destacan asimismo por su variedad, siendo contados los casos de rima musical, esto es, la repetición del mismo giro melódico al final de dos o más frases cuyos textos riman..$^{62}$ Las muestras más claras de este procedimiento las encontramos en las antífonas de laudes In amore jugiter (Figura 4), Contemplatur jugiter e Invitus assumitur. Muchas cadencias son además de tipo galicano, en donde la nota de reposo se alcanza desde el grave. Tal tipo de conducciones, ajenas a la sintaxis gregoriana más clásica, gozaron de especial predilección en la composición cantollanística tardomedieval. ${ }^{63}$

\footnotetext{
${ }^{61}$ Jeanneteau, Los modos gregorianos, p. 362.

${ }^{62}$ Marcy J. Epstein, "Ludovicus decus regnantium: Perspectives on the Rhymed Office", Speculum 53/2 (1978), p. 294.

${ }^{63}$ Hiley, Western Plainchant, p. 275; y Hughes, The Versified Office, pp. 244-245.
}

El repertorio analizado destaca, igualmente, por el alto grado de sofisticación melódica. El discurso vocal fluctúa entre dos registros: uno moderadamente adornado, asociado a las antífonas, y otro de gran profusión melismática, perceptible en los responsorios. El mayor grado de ornamentación melódica de los responsorios es congruente con la estética gregoriana al tratarse de un género concebido para lucimiento del cantor solista. No obstante, creemos que este desigual desarrollo melódico obedece también a la dispar naturaleza de los textos. En efecto, la orientación más panegírica de los responsorios les predispone a recibir un mayor número de notas, las cuales, a la postre, realzan su naturaleza contemplativa. Por el contrario, el sentido netamente narrativo de las antífonas es lo que justifica su mayor cualidad silábica. ${ }^{64}$

De manera ocasional, verificamos una clara correspondencia entre las palabras clave y los melismas más prolongados. Ello ocurre particularmente en el responsorio Aedificavit triplex, donde se resaltan conceptos ligados a la promoción de la vida eremítica y monástica; así, "Aedificavit” (11 notas), "montium" (12 notas) y "monasterium" (7 notas). En algunos de estos desarrollos se atisba el deseo de pintar musicalmente el contenido del texto, si bien creemos aún prematuro hablar de figuralismo por su excepcionalidad. Sirva de ejemplo la musicalización del sustantivo "mons / montis" (montaña). De las cuatro veces que aparece en el oficio, sólo en una sí parece dibujar la silueta de una cadena montañosa; véase Figura 7.

\footnotetext{
${ }^{64}$ Vuori, Räsänen y Heikkinen, The Medieval Offices, pp. 80 y 83.
} 


\section{A MODO DE CONCLUSIÓN: EL ORIGEN DEL OFICIO RIMADO DE SAN FROILÁN}

La investigación emprendida sobre el oficio de san Froilán ha dejado al descubierto la heterogeneidad de estrategias compositivas empleadas en su elaboración. Por un lado, la versión transmitida por Lu parece inclinarse decididamente por el uso de melodías de nueva creación; por otro, los responsorios recogidos en Le9 parten de modelos enraizados en la antigua tradición gregoriana a los que se les ha aplicado la técnica de contrafactum. El texto poético, mientras tanto, se transmite de manera estable en la elección y ordenamiento de las piezas. Esta disparidad de criterios confirma que nos hallamos ante dos procesos separados de composición, no necesariamente coetáneos en el tiempo. Queda patente además que, dentro de este doble proceso, la música posee un menor estatus que el texto, lo que ha condicionado que su desarrollo se atenga a coordenadas más locales. A falta de mayores evidencias, cabe presumir que la composición poética se utilizara por vez primera en León por ser el lugar donde se instituye el culto litúrgico a Froilán, alrededor del último tercio del siglo XII. ${ }^{65}$ Desconocemos si ya desde fecha tan temprana se cantaron estos textos, o bien hubo una fase transitoria en la que se emplearon formularios del Común de un confesor.

Las alusiones a la condición benedictina de Froilán, ausentes en la Vita Froilanis, ${ }^{66}$ plantean una posible paternidad monástica. Dos serían los centros a priori idóneos para situar a sus artífices. En primer lugar, el monasterio cisterciense de Santa María de Moreruela (Zamora), lugar donde Froilán fue honrado como fundador. ${ }^{67}$ Hacia 1175

65 José Ma . Canal Sánchez-Pagín, "San Froilán obispo de León. Ensayo biográfico”, Hispania Sacra, 45/91 (1993), p. 131.

${ }^{66}$ De hecho, en la narración de la Vita lo más que se apunta es que funda un monasterio en la ribera del Esla bajo una regla monástica, sin determinar; véase Martín, "La Vita Froilanis", p. 582.

67 Este monasterio de Santa María de Moreruela no se corresponde con el que fundara Froilán en Moreruela de Tábara. Las indagaciones arqueológicas apuntan a que este cenobio tuvo que cambiar de ubicación a finales del siglo $\mathrm{X}$ a raíz de las razias militares de Almanzor. No parece de todos modos que la comunidad prosperara, pues en 1143 el rey Alfonso VII concede al noble Ponce de Cabrera la villa "largo tiempo desierta" de Moreruela de Frades para albergar allí un monasterio, la futura casa de Santa María de Moreruela; véase Fernando Regueras Grande y Maurilio Pérez González, "Cenobios tabarenses: sobre un nuevo epígrafe localizado en Tábara”, Brigecio: Revista de Estudios de Benavente y sus tierras, 7 (1997), p. 71. sabemos que sus reliquias se encontraban allí, momento en que parte de las mismas pasan a la catedral de León. ${ }^{68}$ El otro gran candidato sería el monasterio benedictino de Sahagún (León), conocido sobre todo por ser núcleo de avanzadilla en la romanización litúrgica de Castilla. ${ }^{69}$ En el ánimo de sus monjes estuvo siempre considerar a Froilán como benedictino, habiendo incluso quienes le atribuían ser miembro de esta comunidad o cofundador al coincidir sus orígenes con los años de su pontificado. ${ }^{70}$ En el siglo XVI tenemos noticia de que esa vinculación benedictina había prendido por la Península Ibérica, ${ }^{71}$ situación que perdura hasta la actualidad. ${ }^{72}$

Quizás el principal obstáculo que encuentra la teoría de la paternidad monástica es que el oficio, tal como nos ha llegado, es de curso secular o romano, aspecto corroborado por las nueve antífonas y nueve responsorios entonados en maitines. No parece factible que su redacción partiera de un presunto arquetipo monástico, hoy perdido, principalmente por la estabilidad con la que se transmiten los textos y la ausencia de irregularidades en el ordenamiento correlativo de modos verificado en las antífonas de maitines. ${ }^{73}$ Los testimonios litúrgicos conservados de

68 Sánchez-Pagín, "San Froilán obispo de León”, p. 128.

69 Juan Pablo Rubio Sadia, Las órdenes religiosas y la introducción del rito romano en la Iglesia de Toledo (Toledo: Instituto Teológico San Ildefonso, Instituto de Estudios VisigóticoMozárabes, 2004), pp. 54-57.

70 Julio de Prado Reyero, Siguiendo las huellas de San Froilán (Salamanca: San Esteban, 1994), pp. 171-172. En su crónica de Sahagún, Fray Romualdo Escalona, Historia del Real Monasterio de Sahagún, sacada de la que dexó escrita el Padre Maestro Fr. Joseph Pérez (Madrid: Joaquín Ibarra, 1782), pp. 25-28, contempla a Froilán solo como monje del monasterio.

${ }^{71}$ Así lo considera el padre Lobera en su biografía del santo, obra que ejerció una enorme influencia en los historiadores posteriores; véase Atanasio de Lobera, Historia de las grandezas de la muy antigua, e insigne ciudad y iglesia de Leon, y de su obispo, y patron sant Froylan, con las del glorioso S. Atilano obispo de Çamora (Valladolid: Diego Fernández de Córdoba, 1596), fols. $16 \mathrm{v}, 17 \mathrm{v}$ y $43 \mathrm{r}$.

${ }^{72}$ En su biografía de 1911, López Peláez, Vida póstuma, p. 169, considera a Froilán "una gloria española y de la Orden Benedictina", mostrando a continuación su perplejidad por que la Congregación de San Benito de Valladolid no haya prescrito su rezo. Prado Reyero, Siguiendo las huellas, p. 138, también lo cita como benedictino.

73 Es relativamente común que la relaboración de oficios en verso implique algún desajuste en el ordenamiento serial de los modos; véase Andrew Hughes, "Modal Order and Disorder in the Rhymed Office", Musica Disciplina, 37 (1983), pp. 29-51. 
ambos cenobios son además reducidos y en su mayoría tardíos en el tiempo. De Santa María de Moreruela no existe constancia de fuentes medievales, ${ }^{74}$ en tanto que Sahagún no registra su culto en el leccionario ms. 9 de la Real Academia de la Historia, copiado entre finales del siglo XII y comienzos del XIII; ni siquiera en el anexo al Propio de los Santos con numerosas devociones hispanas. ${ }^{75}$ Creemos más bien que esas menciones a la profesión benedictina de Froilán fueron una estratagema de la que se sirvió León para subrayar el origen monástico de la institución diocesana. ${ }^{76}$ Es cierto que las alusiones locales dentro del oficio se reducen a una única pieza (la antífona $O$ quanto desiderio), pero aun así son más numerosas que las de emplazamientos monásticos, omitidas por completo. Por ello, y aun con todas las precauciones, nos inclinamos a pensar que la redacción poética responde a una iniciativa esencialmente leonesa.

Por lo que respecta a la música, la resolución de estas cuestiones se revela si cabe más ardua. Guarda bastante verosimilitud que la lectura ofrecida por Le9 sea más antigua, tal vez incluso contemporánea a la propia composición poética. La reutilización de melodías preexistentes es sintomática de una fidelidad hacia modelos del pasado, pero a la vez parece encubrir segundas intenciones; la primera y más evidente, subsanar la desventaja espiritual en la que se hallaba la catedral leonesa frente a la colegiata de San Isidoro, que desde 1063 custodiaba los restos del célebre autor de las Etimologías. La competencia que suponía contar con un santo de tal renombre es lo que, a la postre, avivó el deseo de recuperar el cuer-

${ }^{74}$ En su relato biográfico, López Peláez, Vida póstuma, pp. 162-163, informa de varias fuentes de Moreruela, incluyendo libros de coro. Pese a que no precisa su datación, menciona que no son tan antiguas como el breviario de Lugo.

75 Patrick Henriet, "Sanctoral clunisien et sanctoral hispanique au XIIe siècle, ou de l'ignorance réciproque au syncrétisme. À propos d'un lectionnaire de l'office originaire de Sahagún (fin XIIe s.)", en Scribere sanctorum gesta. Recueil d'études d'hagiographie médiévale offert à G. Philippart, Hagiologia, 3 (Turnhout: Brepols, 2005), pp. 209-259.

76 Semejante hipótesis la esgrime Javier Pérez-Embid Wamba, Hagiología y sociedad en la España medieval. Castilla y León (siglos XI-XIII) (Huelva: Universidad de Huelva, 2002), pp. 191192, para retrasar la copia de la Vita Froilanis a finales del siglo XII. Independientemente de la datación de la Vita, lo que va más allá de este estudio, compartimos la argumentación que subyace en el fondo: la recuperación de la figura de Froilán por esos años responde a una evidente intención de reforzar la posición de la catedral leonesa en el panorama eclesiástico hispano. po de Froilán. Fuera de estas motivaciones religiosas, la maniobra ha de entenderse también como un ardid con el que prestigiar la sede leonesa y, con ello, asegurar una posición ventajosa en la percepción de derechos eclesiásticos. Visto desde esta perspectiva, la elección de melodías preexistentes no resulta fortuita, primero, porque remiten a un modelo de autoridad sancionado por su uso regular en las celebraciones de santos $y$, segundo, porque agiliza el proceso de aprendizaje, lo que no es cuestión baladí si lo que se pretende es afianzar el nuevo oficio.

La elaboración musical de Lu responde a una concepción más moderna. Aquí no reviste tanta importancia ampararse en las antiguas melopeas, pues el rezo está ya consolidado. Lo que se persigue, en cambio, es individualizarlo con respecto a la costumbre observada en otras iglesias, de ahí su inclinación hacia melodías de nueva composición. El análisis previo revela que, en muchos aspectos, su desarrollo es congruente con la estética clásica gregoriana, hecho perceptible en rasgos tales como la moderada tesitura vocal, el uso de melodías-centones o el alto grado de densidad melismática, la cual logra de manera bastante efectiva ensombrecer las simetrías inherentes a la naturaleza poética de los textos. Las innovaciones, también en número elevado, marchan acordes a lo que sucede en otros oficios rimados tardomedievales; entre las más importantes, se encuentran: el ordenamiento correlativo de modos verificado en las antífonas de maitines y laudes, el acentuado dinamismo melódico, que hace excepcionales las recitaciones recto tono, o la mayor regularización fraseológica. Tales cambios, sin embargo, no entrañan menoscabo alguno al texto en su función de basamento de la arquitectura sonora.

La averiguación de la fecha en que fue compuesta la música encuentra un valioso aliado en el propio proceso de escritura de Lu. Como tal, el breviario consta de dos partes: la primera y más antigua de mediados del siglo XIII y la segunda copiada poco después de 1323, que es donde se halla el oficio de san Froilán. ${ }^{77}$ Este marco temporal se correspondería con los términos post quem y ante quem en los que presumiblemente debieron componerse las melodías. Su acusado desarrollo melismático e insensibilidad hacia artificios como la agrupación de notas en torno al acento o el word-painting sugieren que tal hecho se produjera en fecha más cercana al límite anterior.

Como balance final, las redacciones musicales de Le9 y Lu, aun partiendo de premisas diferentes, cumplen

77 Janini, Manuscritos litúrgicos, p. 145 (núm. 168); y Rey Olleros, "El breviario de Lugo", p. 256. 
con creces los fines propuestos: servir de altavoz desde el que proclamar la santidad de Froilán y narrar sus episodios biográficos más relevantes. La naturaleza poética que exhiben sus textos es un elemento incidente en la creación musical, pero no determinante hasta el punto de desfigurar la tradicional fisonomía gregoriana. Quizás el mejor ejemplo lo tengamos en los responsorios de Le9 por el hecho de emplear melodías aplicadas en origen a composiciones en prosa. Esta rica simbiosis entre tradición e innovación representa, en suma, el sello caracterizador y fundante de este repertorio, una afirmación que en buena medida podemos extrapolar a la mayoría de oficios rimados del periodo.

\section{BIBLIOGRAFÍA CITADA}

Bailey, Terence. "Accentual and Cursive Cadences in Gregorian Psalmody". Journal of the American Musicological Society, 29/3 (1976), pp. 463-471.

Björkvall, Gunilla, y Andreas Haug. "Performing Latin Verse. Text and Music in Early Medieval Versified Offices". En The Divine Office in the Latin Middle Ages. Methodology and Source Studies, Regional Developments, Hagiography, editado por Margot E. Fassler y Rebecca A. Baltzer. Oxford: Oxford University Press, 2000, pp. 278-299.

Burón Castro, Taurino. "Fragmentos de códices litúrgicos conservados en el Archivo Histórico Provincial de León”. En León y su historia: miscelánea histórica de temas leoneses, 8 vols. León: Centro de Estudios e Investigación "San Isidoro", 1969-2003, vol. 6 (2000), pp. 149-477.

"El Cabildo de la Catedral, impulsor del culto de san Froilán”. Studium Legionense, 47 (2006), pp. 281-327.

Canal Sánchez-Pagín, José Ma " "San Froilán obispo de León. Ensayo biográfico". Hispania Sacra, 45/91 (1993), pp. 113-146.

Deshusses, Jean, ed. Le Sacramentaire Grégorien: Ses principales formes d'après les plus anciens manuscrits, 3 vols. Fribourg: Éditions Universitaires, 1971-1982.

Dreves, Guido Maria, ed. Analecta Hymnica Medii Aevi XVII. Hymnodia Hiberica. Leipzig: O.R. Reisland, 1894.

Epstein, Marcy J. "Ludovicus decus regnantium: Perspectives on the Rhymed Office". Speculum, 53/2 (1978), pp. 283-334.

Escalona, Romualdo. Historia del Real Monasterio de Sahagún, sacada de la que dexó escrita el Padre Maestro Fr. Joseph Pérez. Madrid: Joaquín Ibarra, 1782.
Fernández Fernández, Xosé. "O misal lucense, singular texto liturxico do Arquivo da Catedral". Lucensia, 6 (1993), pp. 71-84.

Ferreira, Manuel Pedro. "The Lisbon Office for the Translation of St. Vicent". En A Musicological Gift: Libro Homenaje for Jane Morlet Hardie, editado por Kathleen Nelson y Maricarmen Gómez. Lions Bay: The Institute of Mediaeval Music, 2013, pp. 57-86.

Gutiérrez, Carmen Julia. "Procedimientos de creación y adaptación en los himnos litúrgicos medievales en España: la composición de un repertorio". Revista de Musicología, 27/2 (2004), pp. 815-839.

Henriet, Patrick. "Sanctoral clunisien et sanctoral hispanique au XII siècle, ou de l'ignorance réciproque au syncrétisme. À propos d'un lectionnaire de l'office originaire de Sahagún (fin XII ${ }^{e}$ s.)". En Scribere sanctorum gesta. Recueil d'études d'hagiographie médiévale offert à G. Philippart, Hagiologia, 3. Turnhout: Brepols, 2005, pp. 209-259.

Hiley, David. Western Plainchant. Oxford: Clarendon Press, 1993.

Hughes, Andrew. "Modal Order and Disorder in the Rhymed Office". Musica Disciplina, 37 (1983), pp. 29-51.

. "Rhymed Offices". En The Dictionary of the Middle Ages, 10 vols., editado por Joseph R. Strayer. New York: Charles Scribner's Sons, 1982-1989, vol. 10 (1988), pp. 366-377.

. Late Medieval Liturgical Offices. Texts. Subsidia Mediaevalia, 23; Sources and Chants. Subsidia Mediaevalia, 24. Toronto: Pontifical Institute of Medieval Studies, 1994 y 1996.

"Late Medieval Plainchant for the Divine Office". En The New Oxford History of Music. III.1. Music as Concept and Practice in the Late Middle Ages. Oxford: Oxford University Press, 2001, pp. 31-96.

The Versified Office: Sources, Poetry, and Chants, 2 vols. Lions Bay: The Institute of Mediaeval Music, 2011.

Huglo, Michel. Les tonaires: inventaire, analyse, comparaison. Paris: Université de Paris, 1971.

. Les livres de chant liturgique. Typologie des sources du Moyen Âge occidental, 52. Turnhout: Brepols, 1988.

. Les manuscrits du processional. I. Autriche a Espagne. München: G. Henle Verlag, 1999.

Janini, José. Manuscritos litúrgicos de las Bibliotecas de España. I. Castilla y Navarra. Burgos: Aldecoa, 1977. 
Jeanneteau, Jean. Los modos gregorianos. Historia, análisis, estética. Studia Silensia, 11. Silos: Abadía, 1985.

Lapidge, Michael. Bede's Latin Poetry. Oxford Medieval Texts, editado por J. W. Binns, D. d'Avray, M. S. Kempshall y R. C. Love. Oxford: Oxford University Press, 2019.

Lara Lara, Francisco Javier. "Estructuras modales en el Códice Calixtino". En El Códice Calixtino y la música de su tiempo. Actas del simposio organizado por la Fundación Pedro Barrié de la Maza en A Coruña y Santiago de Compostela, 20 - 23 de septiembre de 1999. A Coruña: Fundación Pedro Barrié de la Maza, 2001, pp. 273-310.

Lobera, Atanasio de. Historia de las grandezas de la muy antigua, e insigne ciudad y iglesia de Leon, y de su obispo, y patron sant Froylan, con las del glorioso S. Atilano obispo de Çamora. Valladolid: Diego Fernández de Córdoba, 1596.

López Peláez, Antolín. Vida póstuma de un santo (El culto de San Froilán). Madrid: Imp. Hijos de Gómez Fuentenebro, 1911.

Martín, José Carlos. "La Vita Froilanis episcopi Legionensis (BHL 3180) (s. X): introducción, edición crítica y particularidades lingüísticas". En Parva pro magnis munera: Etudes de littérature latine tardoantique et médiévale offertes à François Dolbeau par ses élèves. Instrumenta patristica et mediaevalia, 51. Turnhout: Brepols, 2009, pp. 561-584.

. "Relatos hagiográficos sobre algunos obispos de la España medieval en traducción: Ildefonso y Julián de Toledo (BHL 3917 y 4554), Isidoro de Sevilla (BHL 4488) y Froilán de León (BHL 3180)". Veleia, 28 (2011), pp. 209-242.

Mews, Constant J., Carol J. Williams, John N. Crossley, y Catherine Jeffreys. Guy of Saint-Denis, Tractatus de tonis. Kalamazoo: Medieval Institute Publications, 2017.

Pérez Rodríguez, Estrella. "Cantus in Laudem Virginis: el oficio poético de Juan Gil de Zamora". Studia Zamorensia, 13 (2014), pp. 109-123.

Pérez-Embid Wamba, Javier. Hagiología y sociedad en la España medieval. Castilla y León (siglos XI-XIII). Huelva: Universidad de Huelva, 2002.

Prado Reyero, Julio de. Siguiendo las huellas de San Froilán. Salamanca: San Esteban, 1994.

Regueras Grande, Fernando, y Maurilio Pérez González. "Cenobios tabarenses: sobre un nuevo epígrafe localizado en Tábara". Brigecio: Revista de Estudios de Benavente y sus tierras, 7 (1997), pp. 65-90.
Rey Olleros, Manuel. "Reminiscencias del culto al apóstol Santiago, a partir del códice Calixtino, en los libros litúrgicos de los siglos XII al XIV en la antigua provincia eclesiástica de Santiago". Tesis doctoral, Universidad de Santiago de Compostela, 2009.

"La notación aquitana en el códice de Lugo (S. XIII): testimonio de un repertorio musical de Galicia (España) y su aplicación pedagógica". Tesis doctoral, Pontificio Istituto di Musica Sacra, 2012.

. "El breviario de Lugo: su música". Annuarium Sancti Iacobi, 1 (2012), pp. 237-286.

Rodríguez, Raimundo. "El códice 52 de la catedral de León y la liturgia". Archivos Leoneses, 6/11 (1952), pp. 103-107.

Rubio Sadia, Juan Pablo. Las órdenes religiosas y la introducción del rito romano en la Iglesia de Toledo. Toledo: Instituto Teológico San Ildefonso, Instituto de Estudios Visigótico-Mozárabes, 2004.

Ruiz Torres, Santiago. "El oficio de la Traslación del apóstol Santiago en la Baja Edad Media: a propósito de un fragmento de antifonario hallado en la catedral de Segovia". Cuadernos de Estudios Gallegos, LVIII/124 (2011), pp. 79-98.

. "La monodia litúrgica entre los siglos XV y XIX. Tradición, transmisión y praxis musical a través del estudio de los libros de coro de la catedral de Segovia". Tesis doctoral, Universidad Complutense de Madrid, 2013.

Smishkewych, Wolodymyr Joseph. "An Online Digital Facsimile of the Lugo Codex". Tesis doctoral, Indiana University, 2013.

Suárez González, Ana. "La biblia visigótica de la catedral de León (códice 6): primeros apuntes para un estudio arqueológico". Estudios Humanísticos. Historia, 10 (2011), pp. 179-196.

Vuori, Hilkka-Lüsa, Marika Räsänen, y Seppo Heikkinen. The Medieval Offices of Saint Thomas Aquinas. DocMus Research Publications, 14. Helsinki: Sibelius Academy, University of the Arts, 2019.

Wagner, Peter. Introduction to the Gregorian Melodies. A Handbook of Plainsong I. London: The Plainsong \& Mediæval Music Society, 1907 ( $2^{\mathrm{a}}$ ed.).

Zapke, Susana. "El oficio de San Indalecio en el antifonario de Santa Cruz de la Serós, s. XI-XII". Aragonia Sacra, 6 (1991), pp. 181-198.

Recibido: 28.10 .2020

Aceptado: 07.06.2021 
